University of Nebraska - Lincoln

DigitalCommons@University of Nebraska - Lincoln

U.S. Department of Veterans Affairs Staff

Publications

U.S. Department of Veterans Affairs

2008

Screening and Surveillance for the Early Detection of Colorectal

Cancer and Adenomatous Polyps, 2008: A Joint Guideline From the American Cancer Society, the US Multi-Society Task Force on Colorectal Cancer, and the American College of Radiology

\author{
Bernard Levin \\ The University of Texas MD Anderson Cancer Center \\ David A. Lieberman \\ Oregon Health and Science University, lieberma@ohsu.edu \\ Beth Mcfarland \\ Mallinckrodt Institute of Radiology, mcfarlandb@mir.wustl.edu \\ Kimberly S. Andrews \\ American Cancer Society \\ Durado Brooks \\ American Cancer Society

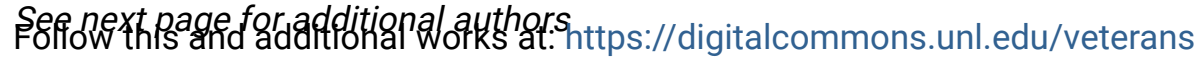

Levin, Bernard; Lieberman, David A.; Mcfarland, Beth; Andrews, Kimberly S.; Brooks, Durado; Bond, John; Dash, Chiranjeev; Giardiello, Francis M.; Glick, Seth; Johnson, David; Johnson, C. Daniel; Levin, Theodore R.; Pickhardt, Perry J.; Rex, Douglas K.; Smith, Robert A.; Thorson, Alan; and Winawer, Sidney J., "Screening and Surveillance for the Early Detection of Colorectal Cancer and Adenomatous Polyps, 2008: A Joint Guideline From the American Cancer Society, the US Multi-Society Task Force on Colorectal Cancer, and the American College of Radiology" (2008). U.S. Department of Veterans Affairs Staff Publications. 45. https://digitalcommons.unl.edu/veterans/45

This Article is brought to you for free and open access by the U.S. Department of Veterans Affairs at DigitalCommons@University of Nebraska - Lincoln. It has been accepted for inclusion in U.S. Department of Veterans Affairs Staff Publications by an authorized administrator of DigitalCommons@University of Nebraska - Lincoln. 


\section{Authors}

Bernard Levin, David A. Lieberman, Beth Mcfarland, Kimberly S. Andrews, Durado Brooks, John Bond, Chiranjeev Dash, Francis M. Giardiello, Seth Glick, David Johnson, C. Daniel Johnson, Theodore R. Levin, Perry J. Pickhardt, Douglas K. Rex, Robert A. Smith, Alan Thorson, and Sidney J. Winawer 
The following article contains new recommendations for colorectal cancer screening, the first set we have published since 2003 (Winawer $S$, Fletcher R, Rex $D$, et al. Colorectal cancer screening and surveillance: clinical guidelines and rationale-update based on new evidence. Gastroenterology 2003;124:544-560.) The current recommendations have emerged through the participation of multiple national societies, taking into consideration newly emerging technologies. Please note the US Multi-Society Task Force (USMTF) represents the American Gastroenterological Association (AGA) Institute, the American Society for Gastrointestinal Endoscopy, and the American College of Gastroenterology. Commissioned originally by the American Cancer Society, this compendium will be published concurrently in CA: A Cancer Journal for Clinicians and reprinted in the June issue of Radiology.

\title{
Screening and Surveillance for the Early Detection of Colorectal Cancer and Adenomatous Polyps, 2008: A Joint Guideline From the American Cancer Society, the US Multi-Society Task Force on Colorectal Cancer, and the American College of Radiology
}

\author{
BERNARD LEVIN, ${ }^{*}$ DAVID A. LIEBERMAN, ${ }^{\ddagger}$ BETH MCFARLAND, ${ }^{\S}$ KIMBERLY S. ANDREWS," DURADO BROOKS," \\ JOHN BOND,"\# CHIRANJEEV DASH, " FRANCIS M. GIARDIELLO," SETH GLICK, ${ }^{* *}$ DAVID JOHNSON, ${ }^{* \star *}$ \\ C. DANIEL JOHNSON, ${ }^{\neq \neq}$THEODORE R. LEVIN, ${ }^{\ddagger \ddagger}$ PERRY J. PICKHARDT, \$\& DOUGLAS K. REX,"II ROBERT A. SMITH," \\ ALAN THORSON, "17 and SIDNEY J. WINAWER ${ }^{\$ \S \&}$ for the American Cancer Society Colorectal Cancer Advisory Group, the \\ US Multi-Society Task Force, and the American College of Radiology Colon Cancer Committee
}

\begin{abstract}
*The University of Texas MD Anderson Cancer Center, Houston, Texas; ${ }^{*}$ Division of Gastroenterology, Oregon Health and Science University, Portland Veterans Medical Center, Portland, Oregon; § Mallinckrodt Institute of Radiology, St Luke's Hospital, Diagnostic Imaging Associates, Chesterfield, Missouri; "Cancer Control Science Department, American Cancer Society, Atlanta, Georgia; "Department of Epidemiology, Rollins School of Public Health, Emory University, Atlanta, Georgia; "Johns Hopkins University School of Medicine, Baltimore, Maryland; **University of Pennsylvania Health System, Philadelphia, Pennsylvania; *¥Gastroenterology Department, Kaiser Permanente Walnut Creek Medical Center, Walnut Creek, California; ${ }^{\S}$ Radiology Department, University of Wisconsin Hospital and Clinics, Madison, Wisconsin; IIIIndiana University, Indianapolis, Indiana; \#\#Gastroenterology Section, Minneapolis Veterans Affairs Medical Center, Minneapolis, Minnesota; ***Eastern Virginia Medical School, Norfolk, Virginia; ${ }^{\sharp \neq \ddagger}$ Radiology Department, Mayo Clinic, Scottsdale, Arizona; ${ }^{17 /}$ Section of Colon and Rectal Surgery, Creighton University School of Medicine, and University of Nebraska College of Medicine, Omaha, Nebraska; and ${ }^{\$ \$ \$}$ Memorial Sloan-Kettering Cancer Center, New York, New York
\end{abstract}

In the United States, colorectal cancer (CRC) is the third most common cancer diagnosed among men and women and the second leading cause of death from cancer. CRC largely can be prevented by the detection and removal of adenomatous polyps, and survival is significantly better when CRC is diagnosed while still localized. In 2006 to 2007, the American Cancer Society, the US Multi-Society Task Force on Colorectal Cancer, and the American College of Radiology came together to develop consensus guidelines for the detection of adenomatous polyps and CRC in asymptomatic average-risk adults. In this update of each organization's guidelines, screening tests are grouped into those that primarily detect cancer early and those that can detect cancer early and also can detect adenomatous polyps, thus providing a greater potential for prevention through polypectomy. When possible, clinicians should make patients aware of the full range of screening options, but at a minimum they should be prepared to offer patients a choice between a screening test that primarily is effective at early cancer detection and a screening test that is effective at both early cancer detection and cancer prevention through the detection and removal of polyps. It is the strong opinion of these 3 organi- zations that colon cancer prevention should be the primary goal of screening.

T $\mathrm{n}$ the United States, colorectal cancer (CRC) is the third most common cancer diagnosed in men and women and the second leading cause of death from cancer. ${ }^{1}$ In 2008 , it is estimated that 148,810 men and women will be diagnosed with CRC and 49,960 will die from this disease. ${ }^{1}$ Five-year survival is $90 \%$ if the disease is diagnosed while still localized (ie, confined to the wall of the bowel) but only $68 \%$ for regional disease (ie, disease

Abbreviations used in this paper: ACR, American College of Radiology; ACRIN, American College of Radiology Imaging Network; ACS, American Cancer Society; CRC, colorectal cancer; CSPY, colonoscopy; CT, computed tomography; CTC, computed tomographic colonography; DCBE, double-contrast barium enema; DIA, DNA integrity analysis; FIT, fecal immunochemical test; FOBT, fecal occult blood test; FSIG, flexible sigmoidoscopy; gFOBT, guaiac-based fecal occult blood test; HPNCC, hereditary nonpolyposis colon cancer; MRI, magnetic resonance imaging; NRDR, National Radiology Data Register; OC, optical colonoscopy; sDNA, stool DNA test; 2D, 2-dimensional; 3D, 3-dimensional; USMSTF, US Multi-Society Task Force on Colorectal Cancer.

(๑) 2008 by the AGA Institute and American Cancer Society, Inc $0016-5085 / 08 / \$ 34.00$

doi:10.1053/j.gastro.2008.02.002 
with lymph node involvement) and only $10 \%$ if distant metastases are present. ${ }^{2}$ Recent trends in CRC incidence and mortality reveal declining rates, which have been attributed to reduced exposure to risk factors, the effect of screening on early detection and prevention through polypectomy, and improved treatment. ${ }^{3}$ However, in the near term, even greater incidence and mortality reductions could be achieved if a greater proportion of adults received regular screening. Although prospective randomized trials and observational studies have demonstrated mortality reductions associated with early detection of invasive disease, as well as removal of adenomatous polyps, ${ }^{4-7}$ a majority of US adults are not receiving regular age- and risk-appropriate screening or have never been screened at all. 8,9

The goal of cancer screening is to reduce mortality through a reduction in incidence of advanced disease. To this end, modern CRC screening can achieve this goal through the detection of early-stage adenocarcinomas and the detection and removal of adenomatous polyps, the latter generally accepted as a nonobligate precursor lesion. Adenomatous polyps are common in adults over age 50 years, but the majority of polyps will not develop into adenocarcinoma; histology and size determine their clinical importance. ${ }^{10,11}$ The most common and clinically important polyps are adenomatous polyps, which represent approximately one half to two thirds of all colorectal polyps and are associated with a higher risk of CRC. Thus, most CRC screening studies evaluate the detection rate of invasive CRCs as well as advanced adenomas, which conventionally are defined as polyps $\geq 10 \mathrm{~mm}$ or histologically having high-grade dysplasia or significant villous components. The evidence for the importance of colorectal polyps in the development of CRC is largely indirect, but nonetheless extensive and convincing, and has been described in detail. ${ }^{11-13}$

Today there is a range of options for CRC screening in the average-risk population, with current technology falling into 2 general categories: stool tests, which include tests for occult blood or exfoliated DNA, and structural exams, which include flexible sigmoidoscopy (FSIG), colonoscopy (CSPY), double-contrast barium enema (DCBE), and computed tomographic colonography (CTC). Stool tests are best suited for the detection of cancer, although they also will deliver positive findings for some advanced adenomas, while the structural exams can achieve the dual goals of detecting adenocarcinoma as well as identifying adenomatous polyps. ${ }^{14}$ These tests may be used alone or in combination to improve sensitivity or, in some instances, to ensure a complete examination of the colon if the initial test cannot be completed. Although screening tests for CRC vary in terms of the degree of supporting evidence, potential efficacy for incidence and mortality reduction, cost-effectiveness, and acceptability, any one of these options applied in a sys- tematic program of regular screening has the potential to significantly reduce deaths from CRC.

Beginning in 1980, the American Cancer Society (ACS) first issued formal guidelines for CRC screening in average-risk adults. ${ }^{15}$ Since then, the ACS has periodically updated its CRC guidelines, ${ }^{16-19}$ including adding recommendations for high-risk individuals in 1997.17 Other organizations also have issued recommendations for CRC screening, most notably the US Preventive Services Task Force, ${ }^{20,21}$ the American College of Radiology (ACR), ${ }^{22,23}$ and the US Multi-Society Task Force on Colorectal Cancer (USMSTF). ${ }^{12,24}$ Recently, the ACS and the USMSTF collaborated on an update of earlier recommendations for postpolypectomy and post-CRC resection surveillance in response to reports suggesting significant deviation from existing recommendations. ${ }^{25,26}$ Since 1997, the organizational guidelines for average-risk adults have grown increasingly similar and represent a broad organizational consensus on the value, options, and methods for periodic screening for CRC.

In the last decade, there has been an increase in the number of technologies available for CRC screening, and in the case of stool tests, there has been growth in the number of commercial versions of guaiac-based and immunochemical-based stool tests (gFOBT and FIT). This growth in options also has been accompanied by changing patterns in the proportion of adults using different tests, with FSIG rates declining, CSPY rates increasing, use of stool blood tests remaining somewhat constant, and use of the DCBE for screening now becoming very uncommon. ${ }^{8}$

There are pros and cons to having a range of options for CRC screening. Despite the fact that the primary barriers to screening are lack of health insurance, lack of physician recommendation, and lack of awareness of the importance of CRC screening, ${ }^{27}$ the historical evidence shows that adults have different preferences and patterns of use among the available CRC screening tests. ${ }^{28-31}$ Although population preferences or resistance to a particular technology may change over time or may be influenced by referring physicians, it also may be true that over time some adults may persist in choosing one technology and rejecting another. Furthermore, at this time not all options are available to the entire population, and transportation, distance, and financial barriers to some screening technologies may endure for some time. Although in principle all adults should have access to the full range of options for CRC screening, the fact that simpler, lower-cost options are available in most settings, whereas other more costly options are not universally available, is a public health advantage. However, for average-risk adults, multiple testing options challenge the referring physician to support an office policy that can manage a broad range of testing choices, their follow-up requirements, and shared decision making related to the options. Shared decision making for multiple screening 
choices is both demanding and time consuming and is complicated by the different characteristics of the tests and the test-specific requirements for individuals undergoing screening. ${ }^{31}$ In addition, the description of benefits is complicated by different performance characteristics of the variants of the occult blood tests and uncertain differences between test performance in research settings and test performance in clinical practice. These challenges have been discussed in the past, ${ }^{19,32}$ and they still are with us today.

In this guideline review, we have reassessed the individual test evidence and comparative evidence for stool tests, including gFOBT, FIT, and stool DNA test (sDNA), and the structural exams, including FSIG, CSPY, DCBE, and CTC, the latter also known as virtual colonoscopy. We have sought to address a number of concerns about the complexity of offering multiple screening options and the degree to which the range of screening options and their performance, costs, and demands on individuals poses a significant challenge for shared decisions. An overriding goal of this update is to provide a practical guideline for physicians to assist with informed decision making related to CRC screening. These guidelines are for individuals at average risk. Individuals with a personal or family history of CRC or adenomas, inflammatory bowel disease, or high-risk genetic syndromes should continue to follow the most recent recommendations for individuals at increased or high risk. ${ }^{24-26}$

\section{Guidelines Development, Methods, and Framework}

The guidelines update process was divided into 2 phases. The first phase focused on the stool tests, including gFOBT, FIT, and sDNA. The second phase of the guidelines update process focused on the structural exams, including FSIG, colonoscopy, DCBE, and CTC. Deliberations about evidence and presentations from experts took place during 2 face-to-face meetings of the the collaborating organizations and invited outside experts and through periodic conference calls. The process relied on earlier evidence-based reviews. ${ }^{12,16-21,24}$ Literature related to CRC screening and specific to individual tests published between January 2002 and March 2007 was identified using MEDLINE (National Library of Medicine) and bibliographies of identified articles. Expert panel members also provided several unpublished abstracts and manuscripts. Where evidence was insufficient or lacking to provide a clear, evidence-based conclusion, final recommendations were based on expert opinion and are so indicated.

While there is clear experimental evidence that screening for CRC with gFOBT is associ-ated with reduced incidence and mortality from CRC screening, ${ }^{5,6,33}$ most of the information supporting the use of the other colorectal screening tests is based on observational and inferential evidence. In this review, priority was placed on studies of asymptomatic average-risk or higher-risk populations that were followed by testing with colonoscopy in all or nearly all study participants as a validation measure.

\section{Summary of the Recommendations}

In this update of guidelines for CRC screening in average-risk adults, the expert panel concluded that a screening test must be able to detect the majority of prevalent or incident cancers at the time of testing. Here we are drawing a new, important distinction between test sensitivity and program sensitivity, the former being the sensitivity achieved in a single test and the latter being the sensitivity achieved over time through serial testing in a program. While cancer screening tests are expected to achieve acceptable levels of sensitivity and specificity, ${ }^{34}$ no specific acceptance threshold for either measure, alone or in combination, has been established for any screening test. $^{35,36}$ Thus, this criterion is based on expert opinion and the following considerations. First, in the judgment of the panel, recent evidence has revealed an unacceptably wide range of sensitivity among some gFOBT strategies, with some practices and tests performing so poorly that the large majority of prevalent cancers are missed at the time of screening. ${ }^{37-39}$ The observation of very low sensitivity for cancer and advanced neoplasia associated with in-office gFOBT led Sox to speculate that CRC mortality rates might be considerably lower today if the quality of gFOBT testing during the previous decade had been higher. ${ }^{40}$ While the literature on other CRC screening tests also reveals a range of sensitivities, even in the presence of significant, correctable, quality-related shortcomings, the majority of invasive cancers still will be detected. Second, a test like gFOBT that demonstrates poor test sensitivity but good program sensitivity depends on high rates of adherence with regular screening. However, many patients have only one test and do not return the following year for programmatic testing. ${ }^{41,42}$ Given the lack of systems to ensure or at least facilitate adherence with recommended regular screening intervals, as well as evidence of suboptimal awareness and engagement of primary care in supporting adherence with screening recommendations, ${ }^{43}$ the panel concluded that it was not realistic at this time to rely on program sensitivity to overcome limitations in test sensitivity. Physicians and institutions should select stool blood tests that have been shown in the scientific literature to detect the majority of prevalent CRCs in an asymptomatic population. If there is not evidence that an available test has met that benchmark, it should not be offered to patients for CRC screening.

Individuals and health care professionals should also understand that screening tests for CRC broadly fall into 2 categories. In one category are the fecal tests (ie, gFOBT, FIT, and sDNA), which are tests that primarily are effective at identifying CRC. Some premalignant ad- 
Table 1. Testing Options for the Early Detection of Colorectal Cancer and Adenomatous Polyps for Asymptomatic Adults Aged 50 Years and Older

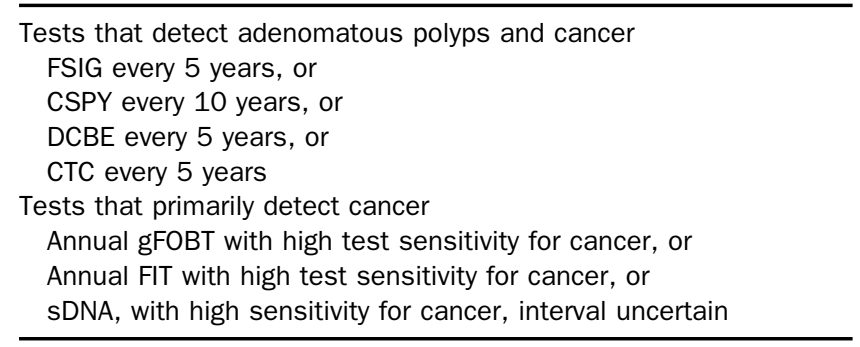

enomatous polyps may be detected, providing an opportunity for polypectomy and the prevention of CRC, but the opportunity for prevention is both limited and incidental and is not the primary goal of CRC screening with these tests. In the second category are the partial or full structural exams (ie, FSIG, CSPY, DCBE, and CTC) ${ }^{44}$ which are tests that are effective at detecting cancer and premalignant adenomatous polyps. These tests differ in complexity and accuracy for the detection of CRC and advanced neoplasia. When performed properly, each of these structural exams has met the standard of detecting at least half of prevalent or incident cancers at the time of testing.

It is the strong opinion of this expert panel that colon cancer prevention should be the primary goal of CRC screening. Tests that are designed to detect both early cancer and adenomatous polyps should be encouraged if resources are available and patients are willing to undergo an invasive test. These tests include the partial or full structural exams mentioned above. These tests require bowel preparation and an office or hospital visit and have various levels of risk to patients. These tests also have limitations, greater patient requirements for successful completion, and potential harms. Significant positive findings on FSIG, DCBE, and CTC require follow-up CSPY.

The panel recognized that some patients will not want to undergo an invasive test that requires bowel preparation, may prefer to have screening in the privacy of their home, or may not have access to the invasive tests due to lack of coverage or local resources. Collection of fecal samples for blood or DNA testing can be performed at home without bowel preparation. However, providers and patients should understand the following limitations and requirements of noninvasive tests:

\&\# These tests are less likely to prevent cancer compared with the invasive tests;

\&\# These tests must be repeated at regular intervals to be effective;

\&\# If the test is abnormal, an invasive test (CSPY) will be needed.
If patients are not willing to have repeated testing or have CSPY if the test is abnormal, these programs will not be effective and should not be recommended.

Based on our review of the historic and recent evidence, the tests in Table 1 are acceptable options for the early detection of CRC and adenomatous polyps for asymptomatic adults aged 50 years and older (also see Table 2).

\section{Screening Tests for the Detection of CRC}

\section{Stool Blood Tests-gFOBT and FIT}

Stool blood tests are conventionally known as fecal occult blood tests (FOBT) because they are designed to detect the presence of occult blood in stool. FOBT fall into 2 primary categories based on the detected analyte: gFOBT and FIT. Blood in the stool is a nonspecific finding but may originate from CRC or larger $(>1$ to 2 $\mathrm{cm})$ polyps. Because small adenomatous polyps do not tend to bleed and bleeding from cancers or large polyps may be intermittent or simply not always detectable in a single sample of stool, the proper use of stool blood tests requires annual testing that consists of collecting specimens ( 2 or 3 , depending on the product) from consecutive bowel movements. ${ }^{18,24,45}$ FIT generally are processed only in a clinical laboratory, whereas gFOBT are processed either in the physician's office or in a clinical laboratory. When performed for CRC screening, a positive gFOBT or FIT requires a diagnostic workup with CSPY to examine the entire colon in order to rule out the presence of cancer or advanced neoplasia.

\section{gFOBT}

gFOBT are the most common stool blood tests in use for CRC screening and the only CRC screening tests for which there is evidence of efficacy from prospective, randomized controlled trials. Guaiac-based tests detect blood in the stool through the pseudoperoxidase activity of heme or hemoglobin, while immunochemical-based tests react to human globin. The usual gFOBT protocol consists of collecting 2 samples from each of 3 consecutive bowel movements at home. Prior to testing with a sensitive guaiac-based test, individuals usually will be instructed to avoid aspirin and other nonsteroidal antiinflammatory drugs, vitamin C, red meat, poultry, fish, and some raw vegetables because of diet-test interactions that can increase the risk of both false-positive and falsenegative (specifically, vitamin C) results. ${ }^{46}$ Collection of all 3 samples is important because test sensitivity improves with each additional stool sample. ${ }^{14}$

gFOBT-Efficacy and Test Performance. Three large, prospective, randomized controlled trials with gFOBT have demonstrated that screened patients have cancers detected at an early and more curable stage than unscreened patients. Over time (8-13 years), each of the 
Table 2. Guidelines for Screening for the Early Detection of Colorectal Cancer and Adenomas for Average-risk Women and Men Aged 50 Years and Older

The following options are acceptable choices for colorectal cancer screening in average-risk adults beginning at age 50 years. Since each of the following tests has inherent characteristics related to prevention potential, accuracy, costs, and potential harms, individuals should have an opportunity to make an informed decision when choosing one of the following options.

In the opinion of the guidelines development committee, colon cancer prevention should be the primary goal of colorectal cancer screening. Tests that are designed to detect both early cancer and adenomatous polyps should be encouraged if resources are available and patients are willing to undergo an invasive test.

\section{Tests that Detect Adenomatous Polyps and Cancer}

\begin{tabular}{|c|c|c|}
\hline Test & Interval & Key Issues for Informed Decisions \\
\hline $\begin{array}{l}\text { FSIG with insertion to } 40 \mathrm{~cm} \text { or to } \\
\text { splenic flexure }\end{array}$ & Every 5 years & $\begin{array}{l}\text { - Complete or partial bowel prep is required } \\
\text { - Sedation usually is not used, so there may be some discomfort during the } \\
\text { procedure } \\
\text { - The protective effect of sigmoidoscopy is primarily limited to the portion of } \\
\text { the colon examined } \\
\text { - Patients should understand that positive findings on sigmoidoscopy } \\
\text { usually result in a referral for CSPY }\end{array}$ \\
\hline CSPY & Every 10 years & $\begin{array}{l}\text { - Complete bowel prep is required } \\
\text { - Conscious sedation is used in most centers; patients will miss a day of } \\
\text { work and will need a chaperone for transportation from the facility } \\
\text { - Risks include perforation and bleeding, which are rare but potentially } \\
\text { serious; most of the risk is associated with polypectomy }\end{array}$ \\
\hline DCBE & Every 5 years & $\begin{array}{l}\text { - Complete bowel prep is required } \\
\text { - If patients have one or more polyps }>6 \mathrm{~mm} \text {, CSPY will be recommended; } \\
\text { follow-up CSPY will require complete bowel prep } \\
\text { - Risks of DCBE are very low; rare cases of perforation have been reported }\end{array}$ \\
\hline CTC & Every 5 years & $\begin{array}{l}\text { - Complete bowel prep is required } \\
\text { - If patients have one or more polyps }>6 \mathrm{~mm} \text {, CSPY will be recommended; } \\
\text { if same day CSPY is not available, a second complete bowel prep will be } \\
\text { required before CSPY } \\
\text { - Risks of CTC are very low; rare cases of perforation have been reported }\end{array}$ \\
\hline
\end{tabular}

Tests that Primarily Detect Cancer

\begin{tabular}{|c|c|c|}
\hline Test & Interval & Key Issues for Informed Decisions \\
\hline gFOBT with high sensitivity for cancer & Annual & $\begin{array}{l}\text { Depending on manufacturer's recommendations, } 2 \text { to } 3 \text { stool samples } \\
\text { collected at home are needed to complete testing; a single sample of } \\
\text { stool gathered during a digital exam in the clinical setting is not an } \\
\text { acceptable stool test and should not be done }\end{array}$ \\
\hline FIT with high sensitivity for cancer & Annual & $\begin{array}{l}\text { - Positive tests are associated with an increased risk of colon cancer and } \\
\text { advanced neoplasia; CSPY should be recommended if the test results are } \\
\text { positive } \\
\text { - If the test is negative, it should be repeated annually } \\
\text { - Patients should understand that one-time testing is likely to be ineffective }\end{array}$ \\
\hline sDNA with high sensitivity for cancer & Interval uncertain & $\begin{array}{l}\text { - An adequate stool sample must be obtained and packaged with } \\
\text { appropriate preservative agents for shipping to the laboratory } \\
\text { - The unit cost of the currently available test is significantly higher than } \\
\text { other forms of stool testing } \\
\text { - If the test is positive, CSPY will be recommended } \\
\text { - If the test is negative, the appropriate interval for a repeat test is } \\
\text { uncertain }\end{array}$ \\
\hline
\end{tabular}

FSIG, flexible sigmoidoscopy; CSPY, colonoscopy; DCBE, double-contrast barium enema; CTC, computed tomography colonography; gFOBT, guaiac-based fecal occult blood test; FIT, fecal immunochemical test; sDNA, stool DNA test.

trials demonstrated significant reductions in CRC mortality of $15 \%$ to $33 \% .5,6,34$ Moreover, incidence reduction of $20 \%$ was demonstrated in one trial (Minnesota) after 18 years of follow-up, which has been attributed to relatively higher rates of CSPY in the study (38\% of subjects in the screened group). ${ }^{7}$

The sensitivity and specificity of a gFOBT has been shown to be highly variable and varies based on the brand or variant of the test; ${ }^{47}$ specimen collection technique; 38 number of samples collected per test ${ }^{14}$ whether or not the stool specimen is rehydrated (ie, adding a drop of water to the slide window before processing);4; and variations in interpretation, screening interval, and other factors. ${ }^{46}$

The reported sensitivity of a single gFOBT varies considerably. In a review by Allison and colleagues, sensitivity for cancer ranged from $37.1 \%$ for unrehydrated Hemoc- 
cult II to $79.4 \%$ for Hemoccult SENSA. ${ }^{47}$ Lieberman and Weiss compared one-time testing with rehydrated Hemoccult II and observed 35.6\% sensitivity for cancer. ${ }^{14}$ In a study comparing gFOBT (unrehydrated Hemoccult II) with sDNA, sensitivity for cancer was only $12.9 \%{ }^{37}$ More recently, Allison and colleagues compared a highsensitivity gFOBT (Hemoccult SENSA) with an FIT and observed $64.3 \%$ sensitivity for cancer and $41.3 \%$ for advanced adenomas. ${ }^{49}$ Thus, the data reveal a range of performance among gFOBT variants that allows them to be grouped into low and high test sensitivity groups. The specificity of gFOBT also is variable, with low test sensitivity gFOBT (such as Hemoccult II) tending to have very high specificity and high test sensitivity gFOBT (such as Hemoccult SENSA) having lower specificity. In a comparison of various stool blood tests, Allison and colleagues observed specificity for cancer and advanced adenomas of $97.7 \%$ and $98.1 \%$, respectively, for Hemoccult II, with a combined specificity for cancer and advanced adenomas of $98.1 \%$. For Hemoccult SENSA, which had greater sensitivity for cancer and advanced adenomas compared with Hemoccult II, specificity for cancer and advanced adenomas was $86.7 \%$ and $87.5 \%$, respectively, with a combined specificity for cancer and advanced adenomas of $87.5 \%{ }^{47}$

A significant limitation of the potential of testing with gFOBT is that it is commonly performed in the physician's office as a single-panel test following a digital rectal exam. ${ }^{39}$ In a recent national survey of primary care physicians, $31.2 \%$ reported using only the in-office method of gFOBT, and an additional $41.2 \%$ of physicians reporting using both the in-office method or the take-home method. While this approach may seem pragmatic, Collins et al demonstrated that sensitivity is only $4.9 \%$ for advanced neoplasia and only $9 \%$ for cancer. ${ }^{38}$ The accuracy of this method is so low that it cannot, under any circumstances or rationale of convenience, be endorsed as a method of CRC screening.

An additional limitation observed in the current use of gFOBT is inadequate follow-up of a positive test. Despite the fact that all existing CRC screening guidelines recommend CSPY follow-up of a positive gFOBT, in the same survey that revealed high rates of in-office gFOBT, nearly one third of physicians reported that they followed up a positive gFOBT with a repeat gFOBT, and a substantial percentage reported that they referred patients to sigmoidoscopy rather than CSPY after a positive gFOBT. Similar patterns of testing and response to positive test results have been reported by patients undergoing athome screening. ${ }^{39}$

gFOBT-Benefits, Limitations, and Harms. Annual testing with gFOBT has been shown to reduce both CRC mortality and incidence. Testing for occult blood is simple and is associated with minimal harm, although any testing with gFOBT is associated with a possibility of a positive test result that will require follow-up with
CSPY, which is associated with a greater risk of harm. The limitation of gFOBT is that many of the individual tests have limited test sensitivity under the best of circumstances, and this sensitivity may be further compromised by poor and incomplete specimen collection and inadequate or improper processing and interpretation. Program sensitivity (ie, the outcome of repeat annual testing) is considerably higher, but the systems to ensure regular annual testing often are not in place to support either the patient or his or her physician to be adherent. Further, testing in the office following a digital rectal exam, which is highly inaccurate, has been common and still may persist at significant levels today. When the test, the testing procedure, or both have very low test sensitivity, and when positive tests are not followed up with CSPY, the potential is high for patients to have a false sense of reassurance after testing. Finally, patients who choose gFOBT for CRC screening must understand that annual testing is required.

Quality Assurance. If patients and their providers select gFOBT for CRC screening, they should be aware of several quality issues based on programmatic performance in clinical trials. First, the test must be performed properly with 3 stool samples obtained at home. A single stool sample FOBT collected after digital rectal exam in the office is not an acceptable screening test, and it is not recommended. Prior to testing with a sensitive guaiac-based test, individuals should be instructed to avoid nonsteroidal anti-inflammatory drugs such as ibuprofen, naproxen, or aspirin (more than one adult aspirin per day) for 7 days prior to testing unless they are on a cardioprotective regimen. There has been debate as to whether additional dietary restrictions reduce compliance with testing and are necessary to reduce the risk of both false-negative and false-positive results. Results of a meta-analysis that examined completion and positivity results found little support for the influence of dietary restrictions on completion or positivity rates, with the exception of completion rates in one study that imposed severe restrictions. However, manufacturers still endorse avoidance of vitamin $\mathrm{C}$ in excess of $250 \mathrm{mg}$ from either supplements or citrus fruits and juices and avoidance of red meats (beef, lamb, and liver) for 3 days before testing. This seems prudent since recent consumption of red meat is associated with increased false positivity, and excess vitamin $\mathrm{C}$ can result in false-negative results. Second, it is critically important that physician offices and laboratories follow recommended quality assurance procedures for test development and interpretation. Although rehydration of gFOBT slides increases sensitivity, it is not recommended because it can adversely affect the readability of the test and also substantially increases the false-positive rate. Sinatra and colleagues observed considerable variation in the interpretation of gFOBT among 13 laboratories in Melbourne, Australia, and concluded that ongoing technician training and review of laboratory 
procedures were important. ${ }^{50}$ Better results may be achieved if guaiac-based tests are routinely processed and interpreted in a clinical laboratory. Third, if the test is positive, patients should be advised to have CSPY. Repeating the stool test or follow-up with non-CSPY tests is inappropriate. Fourth, if the test result is negative, patients should understand that they need to have repeated testing annually.

gFOBT-Conclusions and Recommendations. Annual screening with high-sensitivity gFOBT (such as Hemoccult SENSA) that have been shown in the published peer-reviewed literature to detect a majority of prevalent CRC in an asymptomatic population is an acceptable option for colorectal screening in average-risk adults aged 50 years and older. Any positive test should be followed up with CSPY. Individuals should be informed that annual testing is necessary to achieve the fullest potential of this test and that they will need follow-up CSPY if test results are positive. Screening for CRC with gFOBT in the office following digital rectal exam or as part of a pelvic examination is not recommended and should not be done. Commonly used guaiac tests, with or without rehydration, that have not been shown in the literature to detect a majority of prevalent $\mathrm{CRC}$ at the time of testing are no longer recommended.

\section{FIT}

The concept of applying an immunochemical method to testing stool for occult blood was first proposed in the $1970 \mathrm{~s},{ }^{51}$ and commercialization of the technology began in the 1980s. The use of FIT in the United States has lagged behind some other countries, mostly due to the higher costs associated with FIT compared with gFOBT. However, recently increased reimbursement by Medicare made the use of FIT financially viable and has led to its wider acceptability in the United States. ${ }^{52}$

FIT has several technological advantages when compared with gFOBT. FIT detects human globin, a protein that along with heme constitutes human hemoglobin. Thus, FIT is more specific for human blood than guaiacbased tests, which rely on detection of peroxidase in human blood and also react to the peroxidase that is present in dietary constituents such as rare red meat, cruciferous vegetables, and some fruits. ${ }^{53}$ Further, unlike gFOBT, FIT is not subject to false-negative results in the presence of high-dose vitamin $\mathrm{C}$ supplements, which block the peroxidase reaction. In addition, because globin is degraded by digestive enzymes in the upper gastrointestinal tract, FIT also are more specific for lower gastrointestinal bleeding, thus improving their specificity for CRC. Finally, the sample collection for some variants of FIT are less demanding of patients than gFOBT, requiring fewer samples or less direct handling of stool.

FIT-Efficacy and Test Performance. Recently, a number of new FIT have entered the market, although not all are available in the United States. Some of the new
FIT have been evaluated in comparison with gFOBT in diagnostic accuracy studies with human subjects who all undergo CSPY to define the true presence or absence of neoplasia. Other FIT have been evaluated only on the basis of their ability to detect the presence of certain concentrations of blood in laboratory settings. No FIT has been tested in a randomized trial where the outcome of interest is CRC mortality, nor is it likely, as is the case with CSPY, that such a study will ever be undertaken.

A number of studies over the past 20 years have compared the diagnostic accuracy of various FIT with gFOBT (most often Hemoccult II or Hemoccult SENSA). In this review, we have focused on studies that compared different FIT with Hemoccult SENSA since at present it has the highest sensitivity of currently marketed gFOBT. ${ }^{49,54-58}$ Based on data from these 6 studies, it appears that there are no clear patterns of superior performance in overall test performance between a high-sensitivity guaiac-based test (Hemoccult SENSA) and a variety of FIT.

FIT has been performed in subjects undergoing screening CSPY to determine one-time sensitivity and specificity. Morikawa et al studied 21,805 asymptomatic adults who underwent testing with the Magstream 1000 test (not available in the United States), followed by CSPY. ${ }^{59}$ The Magstream FIT was positive in $5.6 \%$ of patients, with $27.1 \%$ sensitivity for advanced neoplasia and $65.8 \%$ sensitivity for cancer. In a similar study, although not in a totally asymptomatic population, Levi and colleagues sought to measure both sensitivity and specificity of a quantitative FIT and, as well, to measure fecal hemoglobin thresholds most predictive of advanced neoplasia and cancer. ${ }^{58}$ One thousand ambulatory patients, some with and some without symptoms of CRC, who were scheduled for CSPY and who were willing to also undergo an FIT with 3 samples were included in the study. The hemoglobin content of 3 bowel movements was measured. The sensitivity for cancer with 3 FIT samples with a hemoglobin threshold set at $75 \mathrm{ng} / \mathrm{mL}$ was $94.1 \%$. Specificity for cancer was $87.5 \%$. Allison and colleagues recently published results of a comparison of a sensitive gFOBT (Hemoccult SENSA) with an FIT (Hemoccult ICT) for cancer and advanced adenomas in the distal colon in nearly 6000 average-risk subjects who had undergone FSIG. ${ }^{49}$ Both tests showed superior sensitivity for cancer compared with the single-test performance of an unrehydrated gFOBT. The sensitivity for CRC of the FIT and the sensitive gFOBT was $81.8 \%$ and $64.3 \%$, respectively. However, the sensitive gFOBT showed superior performance for advanced adenomas $(41.3 \%)$ compared with FIT (29.5\%). Specificity of FIT tends to be higher than that observed for high-sensitivity gFOBT. For example, in the analysis by Allison et al, the specificity of Hemoccult ICT was $96.9 \%$ for distal cancer, $97.3 \%$ for distal advanced lesions, and $97.5 \%$ for all distal advanced neoplasia. ${ }^{49}$ 
FIT-Benefits, Limitations, and Harms. The spectrum of benefits, limitations, and harms is similar to a gFOBT with high sensitivity. One advantage of FIT over gFOBT appears to be a function of fewer demands on patients undergoing FIT compared with gFOBT. FIT does not require a restricted diet, and the sampling procedures for some forms of FIT are less demanding. ${ }^{60}$

Quality Assurance. If patients and their providers select FIT, they should be aware of several quality issues. Although there are no clinical trials assessing programmatic performance, an effective screening program will depend on repeat testing if the initial test is negative and referral for CSPY if the test is positive. At this time, the optimal number of FIT stool samples is not established, but 2 samples may be superior to one. ${ }^{61}$

FIT-Other Issues. Given the lack of clear difference in test performance in studies conducted to date, policy makers, providers, and patients may want to consider other factors when deciding which occult blood test to use. Relevant other factors include cost (both out-ofpocket and total costs) and likelihood of test completion, which appears to be greater with FIT compared with gFOBT. ${ }^{60}$

FIT-Conclusions and Recommendations. Annual screening with FIT that have been shown in the published peer-reviewed literature to detect a majority of prevalent CRC in an asymptomatic population at the time of testing is an acceptable option for colorectal screening in average-risk adults aged 50 years and older. Any positive test should be followed up with CSPY. Adults should be informed that annual testing is necessary to achieve the fullest potential of this test and that they will need follow-up CSPY if test results are positive.

\section{sDNA}

Knowledge of molecular genomics provides the basis of a new method of CRC screening that tests stool for the presence of known DNA alterations in the adenoma-carcinoma sequence of colorectal carcinogenesis. Adenoma and carcinoma cells that contain altered DNA are continuously shed into the large bowel lumen and passed in the feces. Because DNA is stable in stool, it can be differentiated and isolated from bacterial DNA found in the feces. ${ }^{62}$ No single gene mutation is present in cells shed by every adenoma or cancer. Thus, a multitarget DNA stool assay is required to achieve adequate sensitivity. At present there is only one commercially available sDNA test. The prototype assay of this test (version 1.0) for which most of the published evidence is available consisted of a multiple-marker panel that included 21 separate point mutations in the K-ras, APC, and P53 genes; a probe for BAT-26 (a marker of microsatellite instability); and a marker of DNA integrity analysis (DIA). The sDNA that is currently commercially available is a second generation version of this test (version 1.1) that includes this same marker panel but incorporates several technical advances related to processing and specimen preservation. 63,64 Whereas gFOBT and FIT test a sample of stool or sample of water surrounding stool, the currently available sDNA test requires the entire stool specimen (30-g minimum to ensure an adequate sample of stool for evaluation). Collection kits have been designed to facilitate specimen collection and mailing and to enhance compliance.

sDNA-Efficacy and Test Performance. Several studies on the sensitivity and specificity of sDNA testing for CRC detection have been published utilizing a panel of DNA markers. ${ }^{37,65-69}$ Test sensitivity for CRC in these studies ranged from $52 \%$ to $91 \%$, with specificity ranging from $93 \%$ to $97 \%$. Lower sensitivity in some of these studies has been attributed to suboptimal sensitivity performance of DIA resulting from DNA degradation during transit of specimens to the laboratory. The changes associated with version 1.1 are reported to address these problems. One study utilizing version 1.1 has been published by Whitney et $\mathrm{al}^{63}$ reporting a sensitivity for CRC of $70 \%$.

sDNA has been compared with a low-sensitivity gFOBT in one large prospective study of an average-risk screening cohort. Imperiale et al conducted an investigation in a cohort of 2507 average-risk individuals undergoing colorectal neoplasia screening by 3 modalities: sDNA using the prototype assay (version 1.0), gFOBT (nonrehydrated Hemoccult II), and CSPY. ${ }^{37}$ sDNA testing had statistically significantly better sensitivity for CRC compared with Hemoccult II (52\% vs $13 \%)$ and for all cancers and high-grade dysplasia ( $40.8 \%$ vs $14.1 \%)$, with comparable specificity. In this study, sDNA was much less sensitive in the detection of all advanced adenomas $(15.1 \%)$, defined as a tubular adenoma at least 1 $\mathrm{cm}$ in diameter, an adenoma with a villous histologic appearance, or an adenoma with high-grade dysplasia, although it still showed superior performance to the comparison gFOBT (10.7\%). ${ }^{37}$ Data on program performance of sDNA screening are lacking. Information on the sensitivity and specificity of CRC and adenoma detection comes from an evaluation of results from a single test. Also, the currently available sDNA gene test-version 1.1- has not been rigorously tested in screening cohorts but based on available data can be reasonably assumed to perform as well or better than Version 1.0. ${ }^{63} \mathrm{New}$ version assays with better DNA stabilization and simplified genetic analyses may be more sensitive than version 1.0 but require testing in screening cohorts. ${ }^{70}$

sDNA-Benefits, Limitations, and Harms. The benefit of sDNA is that this methodology has acceptable sensitivity for CRC and is built upon the concept of detecting molecular markers associated with advanced colorectal neoplasia. It is not dependent on the detection of occult bleeding, which is intermittent and nonspecific, and it requires only a single stool collection. Further, newer versions may have better sensitivity as more is 
learned about markers that are common across all prevalent CRCs as well as advanced adenomas. sDNA sampling also is noninvasive and lacks physical harm. Patient and provider acceptance of this technique appears to be high, with available data indicating that sDNA is preferred over other tests by some individuals, and among others testing with sDNA, it is at least as acceptable to patients as testing with gFOBT. ${ }^{29,71}$ Berger et al reported that most individuals undergoing sDNA who completed a mailed survey reported satisfaction with the sDNA testing process, and most reported that they would repeat testing if recommended by their physician. ${ }^{72}$

A clear limitation of sDNA testing for the detection of CRC and large adenomas is that test sensitivity is based on a panel of markers that appears to identify the majority of but not all CRC. Further, it is not known what proportion of advanced adenomas is identified with the current commercial version (version 1.1) of the sDNA test. Other potential limitations that have considerable implications for cost-effectiveness are the unit cost of the current test, ${ }^{73}$ which is much higher than the other stool tests, and the frequency by which the test should be performed, which is uncertain. Currently, the test is under review by the Food and Drug Administration for $510 \mathrm{~K}$ certification but is commercially available under the in-house developed "home brew" category of laboratory tests.

An additional issue is the clinical relevance of a positive genetic test without identification of the cause of the abnormality; this has not been studied systematically. At issue for a test that is based on molecular markers is the degree to which a positive test, with no evidence of advanced lesions upon completion of CSPY, is truly negative or positive for a lesion that is not yet clinically evident. Osborn and Ahlquist have highlighted the fact that inasmuch as cancers exfoliate cells and that these cells can survive the digestive process and ultimately be excreted in stool, high-prevalence supracolonic aerodigestive cancers may also be detected by sDNA. ${ }^{74}$ However, at this time, the significance of a positive test result in a patient with a negative follow-up evaluation is unknown.

Quality Assurance. Individuals should be informed about the benefits and limitations of screening for CRC with sDNA, including the fact that at present the test is more sensitive for cancer than advanced adenomas, that the current panel of markers will not identify all cancers, and that a positive test will need to be followed up with CSPY. Individuals should be made aware that their stool specimen must be packaged and shipped in a customized collection kit that includes a specially designed ice pack. Patients must have access to a working freezer and allow this ice pack to freeze for at least 8 hours prior to use. If the specimen is returned without the ice pack or if there are unforeseen delays in specimen return or processing, the specimen may be rejected.
sDNA-Other Issues. Testing stool for mutated DNA and other markers poses unique challenges in shared decision making. The panel of markers that was evaluated in population studies was not sensitive for all advanced lesions and cancer, and there is uncertainty about improvements in the sensitivity of newer versions for advanced neoplasia and cancer in screening cohorts. At this time, patients will need to be informed that sDNA will detect some but not all advanced lesions and cancers. There also is uncertainty about how positive results without evidence of advanced lesions or cancer on follow-up should be interpreted by patients and whether or not these patients require a different plan for ongoing surveillance. $^{75}$ Additional research is necessary to resolve these questions.

As noted previously, the most informative data on the performance of sDNA testing is from version 1.0, which has been replaced with version 1.1; the newer version uses the same panel of markers but is reported to have improved quality. ${ }^{63,70}$ Newer versions are currently under evaluation, and are reported to have improved sensitivity, with diminution of specificity. The evolution of tests of this type raises important questions as to how performance of successive iterations should be evaluated and whether large prospective studies of asymptomatic patients with follow-up CSPY among all participants are required. Another question worthy of consideration is whether or not including a sensitive gFOBT or FIT at the time of testing would improve sensitivity without adversely affecting specificity. In a recent retrospective analysis of stool samples from patients with CRC and donor controls, combined results from a standard gFOBT and a panel of DNA markers (APC, BAT26, and L-DNA) resulted in a combined sensitivity for cancer of $93 \%$ and specificity of $89 \% .^{76}$

sDNA-Conclusions and Recommendations. In previous assessments of the performance of sDNA, both the ACS and the USMSTF concluded that data were insufficient to recommend screening with sDNA for average-risk individuals.19,24 Based on the accumulation of evidence since the last update of these guidelines, the committee concluded that there are now sufficient data to include sDNA as an acceptable option for CRC screening. As noted above, testing stool for molecular markers is an evolving technology. New iterations of these tests, either technological enhancements of existing tests or completely new test variants, should be carefully evaluated in order to determine that they meet the criteria of detecting a majority of cancers at the time of screening but also have acceptable performance in a screening cohort. While the manufacturer of the one test that is commercially available currently is recommending a 5-year interval for routine screening between examinations with normal results, the committee concluded that there were insufficient data upon which to endorse this interval. Such an interval was judged by the committee to be appropriate only for a test that has very 
high sensitivity for both cancer and adenomatous polyps-a standard that has not been documented for sDNA to date. At this time, further research is needed to determine the interval between negative sDNA examinations. Based on current evidence, the appropriate interval is uncertain.

\section{Tests for the Detection of Adenomas and CRC}

\section{Endoscopy Examinations of the Colon and Rectum-FSIG and CSPY}

FSIG. FSIG is an endoscopic procedure that examines the lower half of the colon lumen. In addition to the standard $60-\mathrm{cm}$ sigmoidoscope, the exam may be performed with a variety of endoscopic instruments, including a colonoscope, an upper endoscope, and a pediatric colonoscope. It is typically performed without sedation and with a more limited bowel preparation than standard CSPY. Since sedation is not required, it can be performed in office-based settings and by nonphysicians, including nurses or physician assistants, provided adequate training has been received. ${ }^{77}$

FSIG-Efficacy and Test Performance. The use of FSIG for CRC screening is supported by high-quality casecontrol and cohort studies, which have been reviewed in detail elsewhere. ${ }^{24}$ In 2 well-known case-control studies, FSIG was associated with a $60 \%$ to $80 \%$ reduction in CRC mortality for the area of the colon within its reach, and this protective effect appears to persist for 10 years or more..$^{4,78}$ A small, randomized trial ${ }^{79}$ and a case-control study ${ }^{80}$ also demonstrated decreased CRC incidence in the sigmoidoscopy-screened group compared with a nonscreened control group. There are 4 prospective, randomized controlled trials ongoing in the United States and Europe, ${ }^{81-84}$ and results are expected in the near future.

Additional evidence supporting the effectiveness of FSIG derives from CSPY studies. FSIG is $60 \%$ to $70 \%$ as sensitive for advanced adenomas and cancers in the colon compared with CSPY. ${ }^{85,86}$ However, this figure varies according to age, with proximal neoplasia becoming more common after age 65 years. ${ }^{87}$ Due to observed differences in the distribution of colonic neoplasia, FSIG may also be less sensitive in women than in men, ${ }^{88}$ although the overall prevalence of advanced colonic neoplasia is lower in women than in men, ${ }^{89}$ and it may be less sensitive in African Americans than in Whites. Several studies have indicated that African Americans have a higher prevalence of proximal lesions than Whites, ${ }^{90,91}$ although a more recent evaluation of proximal lesions in a consecutive series of African American and White adults undergoing FSIG did not observe a statistically significant difference in proximal lesions between the 2 groups among those adults with neoplastic lesions identified during sigmoidoscopy. ${ }^{92}$ In addition, a number of recent studies have documented a lower prevalence of distal colon and rectal lesions in Whites compared with Hispanics and Asians. ${ }^{92,93}$ Differences in the prevalence of distal and proximal lesions based on age, gender, and ethnicity and the benefits and limitations of CRC screening with FSIG among these different groups remain important areas for continued investigation.

The effectiveness of sigmoidoscopy depends on the completion of a high-quality exam. Studies have demonstrated variable adenoma detection rates at screening sigmoidoscopy that are attributed to exam quality and completeness. ${ }^{94}$ Advanced neoplasia has been found within 3 years of a negative sigmoidoscopy in the Prostate, Lung, Colorectal and Ovarian Cancer Screening Trial, raising issues of exam quality. ${ }^{95}$ Although scope insertion to beyond $40 \mathrm{~cm}$ is only one measure of quality, the clinical studies that report adenoma detection and efficacy all achieve this level of insertion. ${ }^{96}$ Studies have demonstrated that deeper levels of insertion are associated with a higher detection rate for advanced neoplasia. ${ }^{86}$ Therefore, the panel recommends that if sigmoidoscopy is performed for CRC screening, insertion to 40 $\mathrm{cm}$ or beyond is required.

Exam quality also depends on the appropriate management of endoscopic findings. The panel recommends that any endoscopist performing sigmoidoscopy should be skilled in obtaining biopsies of polyps to determine histology. The histologic findings are informative for follow-up decision making. There is evidence from 2 large screening studies that if a patient has an adenoma of any size in the distal colon, he or she has an increased risk of proximal advanced neoplasia (2-fold or higher) compared with patients who have no polyps or only hyperplastic polyps in the distal colon. ${ }^{14,85}$ Therefore, we recommend that most patients who have adenomas discovered at sigmoidoscopy should undergo CSPY. If biopsies are not obtained, another strategy is to refer all patients with one or more polyps $>5 \mathrm{~mm}$ for CSPY..$^{97}$

The appropriate interval between normal sigmoidoscopy exams is uncertain and may extend to 10 years, although the protective effect would depend greatly on the quality of the examination. Prior ACS and USMSTF CRC screening guidelines have recommended a 5-year interval between normal FSIG examinations, while recommending a 10-year interval between CSPY examinations. ${ }^{18,24}$ The shorter interval was recommended for FSIG because of concerns about exam quality and completeness in most clinical settings. In settings where an experienced endoscopist performs a complete examination on a well-prepared patient and achieves insertion beyond $40 \mathrm{~cm}$, a 10 -year interval between screening FSIG may be justified. Since these criteria are not routinely achieved in many clinical settings, a 5-year rescreening interval remains the standard recommendation.

The most important limitation in the evidence for FSIG is the lack of a longitudinal head-to-head comparison between FSIG screening and other CRC screening tests, such as CSPY or the different stool blood tests. Apart from the issue of patient preference, a key question 
for screening policy is the incremental benefit of CSPY over FSIG, given the higher direct medical and indirect costs of CSPY and the higher risk of complications with CSPY. 98

FSIG-Benefits, Limitations, and Harms. The chief advantage of FSIG is that it can be performed with a simple preparation (2 Fleet enemas), without sedation, and by a variety of examiners in diverse settings. With respect to distal bowel cleansing, the use of enemas is often imperfect, and superior bowel cleansing is achieved with the more thorough oral sodium phosphate procedure. Patients have reported a more favorable experience with the oral preparation compared with the enemas. ${ }^{99}$ The absence of sedation is perceived by some patients as an advantage and by others as a disadvantage, although in one series a greater percentage of patients undergoing sigmoidoscopy reported periprocedural discomfort (during and postexam) compared with patients undergoing CSPY. ${ }^{100}$ Moreover, lack of sedation is associated with greater patient discomfort and greater patient reluctance to undergo the examination for future screening. 100

An additional limitation of FSIG is that there may be considerable variation both in depth of insertion of the scope and in adenoma detection at FSIG between different examiners, ${ }^{94,101}$ and this may reduce the effectiveness of FSIG for CRC screening, especially in practice settings of low volume. Quality assurance is an important issue for flexible sigmoidoscopists and has been reviewed in detail elsewhere. ${ }^{77}$ Providers should be well trained and should exceed the published American Society for Gastrointestinal Endoscopy standards for a minimum number of training examinations prior to performing sigmoidoscopy without supervision.

The chief limitation of FSIG is that it does not examine the entire colon but, under optimal conditions, only the rectum, sigmoid, and descending colon. However, several lines of evidence support the idea that the incremental benefit of CSPY is less than simply the difference in sensitivity for advanced adenomas between CSPY and FSIG because many patients with small distal adenomas will receive CSPY, which may result in discovery of proximal advanced adenomas and cancer. The complications of FSIG include colonic perforation, even if no biopsy or polypectomy is performed, but this occurs in fewer than one in 20,000 examinations. ${ }^{82,102}$

Quality Assurance. Quality indicators for FSIG have been previously published. ${ }^{77}$ Key elements include (1) appropriate training of endoscopists; (2) satisfactory examination rates to beyond $40 \mathrm{~cm}$; (3) expected adenoma detection rates based on age and gender; and (4) ability to biopsy suspected adenomas. The effectiveness of an FSIG program is based on the assumption that if an adenoma is detected in the sigmoid colon or rectum, the patient would be referred for total CSPY. Patients should fully understand that in most circumstances CSPY will be recommended if an adenoma is detected during FSIG and that if they are unwilling to accept referral to CSPY, they should have a different form of screening.

FSIG-Other Issues. FSIG use in the United States has been decreasing in the recent decade, coincident with a rise in CSPY usage. An analysis of Medicare data from the years 1993 to 2002 demonstrated a 54\% decrease in sigmoidoscopy use between the earliest and latest periods studied and a more than 6-fold increase in CSPY usage over the same time frame. ${ }^{103}$ Other data from endoscopic facilities across the United States collected and analyzed by investigators from the Centers for Disease Control and Prevention estimated that approximately 2.8 million FSIG examinations and 14.2 million CSPY examinations were performed in 2002.104 Low reimbursement and a shortage of adequately trained examiners are 2 barriers to the availability of FSIG. ${ }^{30,105}$ In settings where reimbursement rates have not been a concern and where nurse endoscopists have been employed, high rates of FSIG utilization have been achieved. ${ }^{106}$

FSIG-Conclusion and Recommendations. FSIG can result in the identification of the majority of prevalent CRC at the time of screening, when the examination reaches the splenic flexure or beyond $40 \mathrm{~cm}$ as a reasonable target for insertion and when adenomas in the distal colon are used as an indication for the need for CSPY. Although the appropriate interval between normal examinations is uncertain, FSIG is recommended to be performed for screening every 5 years in most clinical settings due to concerns about exam quality and completeness. FSIG can be performed alone, or consideration can be given to combining FSIG performed every 5 years with a highly sensitive gFOBT or FIT performed annually. In highquality centers (such as the program operated by Kaiser Permanente in California) where procedures are conducted by properly trained and experienced endoscopists who document regular insertion beyond $40 \mathrm{~cm}$ with a good bowel preparation, a 10-year interval between negative exams may be reasonable.

Individuals should be informed about the limitations of FSIG, including the fact that it examines only the distal colon; that there is a risk, albeit small, of perforation; and that they may experience discomfort during and after the examination. Patients should also understand that the examination achieves higher quality when bowel cleansing follows the same protocol as that for CSPY. Finally, patients should be informed that positive test findings will need to be followed up with CSPY.

CSPY. CSPY is one of the most commonly performed medical procedures in the United States, with estimates of up to 14 million procedures performed in 2003. ${ }^{104}$ CSPY allows direct mucosal inspection of the entire colon from the appendiceal orifice to the dentate line and same-session biopsy sampling or definitive treatment by polypectomy in the case of precancerous polyps and some early-stage cancers. 
The modern colonoscope is capable of examining the entire bowel, with the examination terminating at the cecum. Patients generally adopt a liquid diet one or more days before the examination, followed by either ingestion of oral lavage solutions or saline laxatives to stimulate bowel movements until the bowel is clean. Proper bowel preparation is a critical element in the accuracy and cost-effectiveness of screening with CSPY. ${ }^{107}$ It is common for the patient to receive a mild sedative prior to the procedure, but it is not essential for those who tolerate the procedure with only mild discomfort. ${ }^{108}$

CSPY-Efficacy and Test Performance. There are no prospective, randomized controlled trials of screening CSPY for the reduction in incidence or mortality of CRC; however, because CSPY is used to evaluate other positive screening tests, there is evidence to indicate that CSPY and polypectomy result in incidence reductions in randomized controlled trials of other screening tests. The University of Minnesota randomized controlled trial of FOBT observed a $20 \%$ reduction in incidence of CRC, which the authors attribute to CSPY and polypectomy in patients with a positive FOBT. $^{7}$ In a randomized controlled trial of FSIG versus no screening and with follow-up CSPY and polypectomy performed for any polyp detected at sigmoidoscopy, the screening group experienced an $80 \%$ incidence reduction in CRC. ${ }^{79}$

Case-control studies cited above of sigmoidoscopy and polypectomy in screening populations also are considered to provide supporting evidence for CSPY because of the similarity of the examinations in the distal colon. In a case-control study of CSPY in the US VA population, CSPY in symptomatic patients was associated with a $50 \%$ reduction in mortality. 109

The evaluation of incidence rates of CRC in adenoma cohorts after baseline CSPY and polypectomy is another form of evidence commonly cited to support CSPY for CRC screening. In the National Polyp Study, the incidence of CRC after clearing CSPY was reduced by $76 \%$ to 90\% compared with 3 nonconcurrent reference populations. ${ }^{110}$ In an Italian adenoma cohort study with removal of at least one adenoma $\geq 5 \mathrm{~mm}$, there was an $80 \%$ reduction in CRC incidence compared with expected incidence in a reference population. ${ }^{111}$ However, not all studies have shown the same level of protection. Combined data from 3 US chemoprevention trials showed incidence rates of CRC after clearing CSPY approximately 4 times that seen in the National Polyp Study, with no reduction in CRC incidence compared with data from the Surveillance Epidemiology and End Results (SEER) database in the United States, ${ }^{112}$ and 2 US dietary intervention trials also showed higher rates of incident CRC after clearing CSPY than were observed in the National Polyp Study. ${ }^{113,114}$ These differences may reflect exclusion of patients with sessile adenomas $>3 \mathrm{~cm}$ in the National Polyp Study, more effective baseline clearing (13\% of patients in the National Polyp Study had 2 or more baseline CSPY to complete clearing), or unmeasured differences in the average quality of CSPY between the studies.

Overall, the data support the conclusion that CSPY with clearing of neoplasms by polypectomy has a significant impact on CRC incidence and thus, by extension, mortality. The magnitude of the protective impact is uncertain; it is not absolute, nor are apparent failures well understood. In a study of 35,000 symptomatic patients in Manitoba who had undergone a negative CSPY and who then were followed for 10 years, the investigators observed significant reductions in CRC incidence over time, but the incidence reductions were less than $50 \%$ for each of the first 5 years and no more than $72 \%$ by 10 years. These findings suggest detection failures during the initial, apparently normal, CSPY.

CSPY-Benefits, Limitations, and Harms. A principal benefit of CSPY is that it allows for a full structural examination of the colon and rectum in a single session and for the detection of colorectal polyps and cancers accompanied by biopsy or polypectomy. All other forms of screening, if positive, require CSPY as a second procedure.

Patient surveys indicate that patients willing to undergo invasive testing tend to choose CSPY as their preferred test. ${ }^{71}$ In addition to being a complete examination of the colon, individuals may also regard sedation during the procedure as an advantage. Patients in the same practice who had undergone unsedated FSIG screening were more than twice as likely to say that they would not return for additional screening compared with those who had undergone CSPY with sedation. ${ }^{100}$

CSPY has several limitations. It requires one or more days of dietary preparation and bowel cleansing, usually a day dedicated to the examination, and because of sedation, a chaperone is needed for transportation. It is an invasive procedure, and surveys indicate that a significant percentage of adults prefer other noninvasive options for CRC screening. ${ }^{71,115,116}$ Effective performance of the procedure is dependent on thorough bowel preparation, which is often perceived as the most unpleasant part of the CSPY process by those who have undergone the test. Limitations with regard to detection of neoplasia have been previously discussed, and the fact that CSPY is operator skill dependent is another significant limitation. Patients are generally poorly informed about the problem of variable performance of the procedure and are unaware of the skill level of their endoscopists. Formal quality assurance programs do not exist, and the current reimbursement system for CSPY does not reward careful examination but tends to reward rapidly performed examinations and repeated examinations at unnecessarily short intervals. ${ }^{117}$ Polypectomy is sometimes ineffective in eradicating polyps, a factor that has been implicated as the cause of up to $25 \%$ of interval cancers. ${ }^{118,119}$ Finally, CSPY is not an infallible "gold standard." Controlled 
studies have shown the CSPY miss rate for large adenomas ( $\geq 10 \mathrm{~mm}$ ) to be $6 \%$ to $12 \% .120,121$ The reported CSPY miss rate for cancer is about $5 \%{ }^{120,122}$

CSPY can result in significant harm, most often associated with polypectomy, and the most common serious complication is postpolypectomy bleeding. The risk of postpolypectomy bleeding is increased with large polyp size and proximal colon location; however, small polyp bleeds are more numerous than large polyp bleeds because small polyps are so numerous. Another significant risk associated with CSPY is perforation. Perforation increases with increasing age and the presence of diverticular disease and was recently estimated to occur in 1 in 500 of a Medicare population and approximately 1 in 1000 screened patients overall. ${ }^{123}$ Because of the age effect, perforation rates measured in the Medicare population may overestimate the overall risk of perforation in CSPY; however, a large study in the Northern California Kaiser Permanente population also identified a perforation rate of 1 in $1000 . .^{98}$ In addition, cardiopulmonary complications such as cardiac arrhythmias, hypotension, and oxygen desaturation may occur, although these events rarely result in hospitalization. Cardiopulmonary complications represent about one half of all adverse events that occur during CSPY and usually are related to sedation. ${ }^{124}$ Thus, while screening CSPY has established benefits with regard to the detection of adenomas and cancer, complications related to CSPY are a significant public health challenge.

Quality Assurance. Recent publications have highlighted criteria for best practices and important quality indicators for CSPY. ${ }^{124-126}$ High-quality CSPY depends on (1) appropriate training and experience; (2) proper documentation of risk assessment; (3) complete exam to the cecum with adequate mucosal visualization and bowel preparation; (4) ability to detect and remove polyps safely; (5) documentation of polypoid lesions and methods of removal; (6) timely and appropriate management of adverse events; (7) appropriate follow-up of histopathology findings; and (8) appropriate recommendation for surveillance or repeat screening based on published guidelines. Although CSPY is commonly used for screening, diagnosis, and therapy, until recently there was no standardized reporting system for this procedure. To enhance clear communication about CSPY findings between health care professionals and to facilitate quality improvement programs, the Quality Assurance Task Group of the National Colorectal Cancer Roundtable developed a reporting and data system for CSPY based on previously published continuous quality improvement indicators. ${ }^{126}$

CSPY-Other Issues. CSPY in the United States is performed by the overwhelming majority of gastroenterologists, most colorectal surgeons, many general surgeons, and a small percentage of primary care physicians. CSPY volumes have risen steadily in the United States, while volumes for FSIG and DCBE have declined substantially in the past decade, and FOBT has remained relatively stable, although a small decline in the rate was observed among women. ${ }^{8,127}$ CSPY is offered in the vast majority of American hospitals and is also widely performed in ambulatory surgery centers and in physicians' offices in some parts of the country. A recent survey of American colonoscopists suggested that capacity could be increased from the present 14 million annual procedures to 22 million with currently available resources, ${ }^{104}$ although the methodology behind this estimate has been criticized, ${ }^{128}$ and other estimates of capacity are less optimistic regarding capacity. ${ }^{129,130}$ In the short term, CSPY capacity appears sufficient to handle slow increases in demand for the majority of the US population, although the capacity to handle a sharp increase in demand for screening or diagnostic/therapeutic CSPY overall is uncertain and likely highly variable geographically.

Some of the limitations in the availability of CSPY for screening potentially could be overcome by more appropriate use of surveillance CSPY after polyp resection, which has been shown to be excessive among gastroenterologists, and particularly among general surgeons and primary care physicians. ${ }^{117,131}$ Excessive rates of shortterm follow-up after polypectomy, especially for small lesions, also likely diminish the cost-effectiveness of CSPY. For these reasons, the ACS and USMSTF recently updated and further clarified recommendations for postpolypectomy surveillance. ${ }^{25}$ The case against serial shortterm follow-up strategies rests on observations that over the short term the risk of significant growth of adenomas is quite low. However, because there is uncertainty about the natural history of small colorectal adenomas and perhaps because of a desire to err on the side of prudence, a significant percentage of clinicians recommends follow-up intervals that are considerably shorter than recommended, and surveillance intervals often are not adjusted for subsequent negative findings. ${ }^{117}$ Recent guideline recommendations continue to expand the interval between follow-up CSPY examinations in patients with low-risk adenomas. ${ }^{26}$

CSPY-Conclusions and Recommendations. The appropriate interval between negative CSPY screening exams is uncertain because of lack of long-term follow-up data. At present, CSPY every 10 years is an acceptable option for CRC screening in average-risk adults beginning at age 50 years. Individuals should be informed about the limitations of CSPY, including the fact that it may miss some cancers and significant adenomas, and that there is a risk, albeit small, of perforation, hemorrhage (following polypectomy), subsequent hospitalization, and in very rare circumstances, more serious harm. A full bowel cleansing is necessary prior to CSPY. Sedation usually is used to minimize discomfort during the examination, and thus a chaperone is required to provide transportation after the examination. 


\section{Imaging Examinations of the Colon and Rectum-DCBE and CTC}

DCBE. The DCBE, sometimes referred to as aircontrast barium enema, evaluates the colon in its entirety by coating the mucosal surface with high-density barium and distending the colon with air introduced through a flexible catheter that is inserted into the rectum. Multiple radiographs are acquired while varying the patient position during direct fluoroscopic evaluation and subsequently with conventional radiographic equipment. Colonic preparation, usually a 24-hour dietary and laxative regimen, is essential for an optimal examination. Sedation is not utilized, and the duration of the procedure averages about 20 to 40 minutes. Patients may experience mild to moderate discomfort during and after the procedure, but a prompt return to normal activity is typical.

DCBE was contemporaneously adopted as a CRC screening option by the Multi-Society Gastroenterology Consortium and the ACS in 1997 and has continued to be included among the recommended screening options in periodic updates of those guidelines ${ }^{12,17,24,132}$ as well as those of the US Preventive Services Task Force. ${ }^{21}$ It is also considered appropriate for screening by the ACR. ${ }^{133}$ CRC screening of the average-risk population with DCBE also has been a designated Medicare benefit since 1997. ${ }^{134}$

$D C B E-E f f i c a c y$ and Test Performance. There have been no randomized controlled trials evaluating the efficacy of DCBE as a primary screening modality to reduce incidence or mortality from CRC in average-risk adults, and there also are no case-control studies evaluating the performance of DCBE. Further, the existing literature describing the test performance of DCBE also is limited by study designs that are retrospective and commonly do not report findings from an asymptomatic or averagerisk population. ${ }^{135,136}$ In some reports, asymptomatic individuals were selected for investigation during neoplasm surveillance or after a prior screening test (eg, FSIG or FOBT). Finally, similar to the literature related to other CRC screening technologies, the DCBE literature varies considerably in terms of measurement and outcome metrics (ie, polyps, cancers, all neoplasms, adenomas, size categorizations, etc), and these measurements may be estimated by lesion or by population.

Most studies evaluating the cancer detection capability of DCBE utilized a methodology in which all patients in an institution- or population-based database that had been diagnosed with CRC were assessed for a history of a prior DCBE within a defined time frame, the length of which was not consistent between studies but usually ranged from 2 to 5 years. The assumption was that missed cancers on DCBE would subsequently be clinically detected. The majority of these studies showed sensitivity for cancer of $85 \%$ to $97 \% .{ }^{137-150}$

Review of the literature concerning the performance of DCBE for polyps is more difficult due to the described biases and heterogeneity of study design; in particular, the target lesion and thresholds considered clinically significant often varied based upon size and/or morphology. Two studies involving truly asymptomatic individuals were performed in surveillance groups with a history of prior adenoma removal. ${ }^{151,152}$ These demonstrated sensitivities of $48 \%(\mathrm{n}=23)$ for adenomas $\geq 1 \mathrm{~cm}$ and $73 \%$ (n $=56$ ) for adenomas $>7 \mathrm{~mm}$, respectively. It should be noted that in the former study the DCBE detected 75\% (6 of 8) with advanced histology. ${ }^{153}$

DCBE-Benefits, Limitations, and Harms. The potential benefits derived from the DCBE are that it evaluates the entire colon in almost all cases and can detect most cancers and the majority of significant polyps. DCBE also provides an opportunity for a full structural examination for individuals for whom CSPY has either failed or is contraindicated.

DCBE has several limitations. The acceptability of DCBE may be limited by the requirement for extensive colonic preparation, and some patients experience discomfort during and after the procedure. Suboptimal preparation can reduce both sensitivity and specificity. Further, there is no opportunity for biopsy or polypectomy, and any individual with findings of polyps $\geq 6 \mathrm{~mm}$ on DCBE should undergo CSPY. The lower sensitivity for significant adenomas when compared with CSPY may result in less favorable outcomes regarding morbidity and mortality from CRC. DCBE is also limited by the operator dependence of the radiologist or technologist performing the examination, as well as by the radiologist interpreting the examination. DCBE is a relatively safe procedure with a lower perforation rate when compared with CSPY ( 1 of 25,000 vs 1 of 1000 to 2000). ${ }^{154}$

Quality Assurance. The DCBE is a full structural examination of the entire colon that can be performed by radiologists or radiology residents and trained technicians under the supervision of a radiologist. Factors that can affect the quality of the DCBE examination include (1) ability to fully evaluate the entire colon due to lack of retained barium or collapse of segments of the colon, (2) adequacy of the bowel preparation, (3) patient's ability to stand and be imaged in prone and supine positions, and (4) reader's experience in interpretation. Caution is advised when performing a DCBE on the same day after polypectomy to avoid a perforation. The ACR has published guidelines that detail the basic requisites for a high-quality examination, ${ }^{155}$ as well as a quality assurance manual for the DCBE. ${ }^{155}$ Interaction with referring physicians to correlate radiologic findings with endoscopic and/or surgical outcomes may also be an effective ongoing quality assurance in clinical practice.

$D C B E-O t h e r$ Issues. It is likely that the decline in the use of DCBE for CRC screening in average-risk adults will continue. ${ }^{156-158}$ This decline in the utilization of DCBE has had an impact on training programs, as radiology residents have had less opportunity to develop the necessary skills to perform the procedure properly. More- 
over, although there likely are sufficient numbers of radiologists in clinical practice who are available currently to perform DCBE studies, there has been a decline in radiologists' enthusiasm for the DCBE due to its laborintensive nature, the low reimbursement rate, and greater interest in newer and more complex technologies such as computed tomography (CT) and magnetic resonance imaging (MRI). Based on these trends, it is likely that in the next 5 years, there will be even fewer radiologists adequately trained to perform this procedure due to the low volume of DCBE studies currently being requested, as well as low professional interest. At present, the DCBE remains an option for direct imaging of the entire colon and may be of particular value where CSPY resources are limited or CSPY is contraindicated or less likely to be successful (eg, prior incomplete CSPY, prior pelvic surgery, etc).

DCBE-Conclusions and Recommendations. DCBE every 5 years is an acceptable option for CRC screening in average-risk adults aged 50 years and older. Discussions with patients should include a description of the test characteristics, the importance of adherence to a thorough colon cleansing, test accuracy, the likelihood of a positive test, and the need for subsequent CSPY if the test is abnormal. The choice of DCBE for screening can be made on an individual basis, depending on factors such as personal preference, cost, and the local availability of trained radiologists able to offer a high-quality examination.

CTC. CTC, also referred to as virtual coloscopy, is a minimally invasive imaging examination of the entire colon and rectum. CTC uses CT to acquire images and advanced 2-dimensional (2D) and 3-dimensional (3D) image display techniques for interpretation. Since its introduction in the mid-1990s, there have been rapid advancements in CTC technology. Multidetector CT now permits image acquisition of thin 1- to 2-mm slices of the entire large intestine well within breath-hold imaging times. Computer imaging graphics allow for visualization of $3 \mathrm{D}$ endoscopic flight paths through the inside of the colon, which are simultaneously viewed with interactive $2 \mathrm{D}$ images. The integrated use of the $3 \mathrm{D}$ and $2 \mathrm{D}$ techniques allows for ease of polyp detection, as well as characterization of lesion density and location. The 2D images also allow for limited evaluation of the extracolonic structures.

Adequate bowel preparation and gaseous distention of the colon are essential to ensure a successful examination. Patients typically undergo full cathartic preparation along with a clear liquid diet the day before the study, similar to the requirements for CSPY. Tagging of residual solid stool and fluid with barium and/or iodine oral contrast agents is being increasingly used and validated in large trials. At CT, a small-caliber rectal catheter is inserted into the rectum, followed by automated or manual insufflation of room air or carbon dioxide. Intravenous contrast generally is not given to patients undergo- ing screening but can be helpful in some patients with more advanced symptoms. Typically, the entire procedure on the CT table takes approximately 10 minutes, with no sedation or recovery time needed. Research into noncathartic approaches to minimize the bowel preparation is under way, but this technique has not yet been validated in a multicenter screening trial. ${ }^{159-161}$ However, under conditions where same-day or next-day referral for CSPY would be possible, one drawback of noncathartic CTC is that a cathartic bowel preparation would still be required prior to removal of polyps.

CTC-Efficacy and Test Performance. No prospective, randomized, controlled clinical trial has been initiated (nor is one planned) to directly demonstrate the efficacy of CTC in reducing mortality from CRC. Given the cumulative body of evidence in support of CRC screening for reducing mortality and the value of polypectomy in reducing incidence, studies of CTC have focused on the detection of advanced neoplasia.

The test performance characteristics of CTC for polyp detection are derived by using optical colonoscopy (OC) as the reference standard. Early single-center CTC clinical trials involving small, polyp-rich cohorts ${ }^{162-164}$ provided encouraging initial results and served as proof of concept that paved the way for larger multicenter screening trials. Two early trials by Cotton et $\mathrm{al}^{165}$ and Rockey et al ${ }^{166}$ included approximately 600 subjects each and observed per-patient sensitivity for large polyps of 55\% and 59\%, respectively. However, these 2 studies did not evaluate screening in an asymptomatic population, nor did they apply the latest CTC techniques. A more recently initiated multi-institutional screening trial using more advanced CTC techniques demonstrated more favorable performance. Pickhardt et al studied 1233 asymptomatic adults and introduced the techniques of stool tagging and primary $3 \mathrm{D}$ polyp detection, neither of which were used in the 2 earlier multi-institutional trials. ${ }^{167}$ This trial reported a 94\% sensitivity for large adenomas, with a per-patient sensitivity for adenomas $\geq 6 \mathrm{~mm}$ of $89 \%$.

In 2005, 2 meta-analyses reviewed the cumulative published CTC performance data, including both high-risk and screening cohorts, with one analysis representing 33 studies on 6393 patients. ${ }^{168,169}$ On a per-patient basis, pooled CTC sensitivity and specificity for large $(\geq 10$ $\mathrm{mm}$ ) polyps was found to be $85 \%$ to $93 \%$ and $97 \%$, respectively. Pooled sensitivity and specificity for detection of small polyps ( 6 to $9 \mathrm{~mm}$ ) was $70 \%$ to $86 \%$ and $86 \%$ to $93 \%$, respectively. Of note, the pooled CTC sensitivity for invasive CRC was $96 \%,{ }^{168}$ comparable with the reported sensitivity for OC. ${ }^{119,121}$

There also are a number of CTC trials currently in progress within the United States and Europe. Initial results from smaller screening trials utilizing $3 \mathrm{D}$ polyp detection by Cash et $\mathrm{al}^{170}$ and Graser et $\mathrm{al}^{171}$ have shown CTC performance characteristics similar to that of Pickhardt et al, providing at least a measure of independent 
validation for this screening technique. Also of particular interest is the recently completed ACRIN Study 6664: National CT Colonography Trial, which is sponsored and funded by the National Cancer Institute. The primary aim of this trial was to assess CTC performance for large adenomas and advanced neoplasia in a large screening cohort of 2500 patients across 15 institutions. State-ofthe-art techniques included oral contrast tagging, colonic distention with automated carbon dioxide delivery, multidetector row CT ( $\geq 16$ slice) with thin collimation, and both 2D and 3D polyp detection on dedicated CTC software systems. Preliminary findings announced at the 2007 annual meeting of ACRIN on September 28, 2007, were consistent with other recent studies using state-ofthe-art techniques.

Beyond validation, a recent study demonstrated the efficacy of CTC to select patients who would benefit from therapeutic polypectomy. Kim et al recently reported comparative results from primary CTC (with selective recommendation for therapeutic CSPY) and primary OC screening arms among 3120 and 3163 mostly asymptomatic adults, respectively. ${ }^{172}$ Although this study did not randomize participants to CTC versus OC, apart from a slightly higher proportion of individuals with a family history in the OC group, the 2 groups were similar. Similar rates of advanced neoplasia were found in each group, with $3.2 \%$ in the CTC group and $3.4 \%$ in the OC group. ${ }^{172}$

CTC-Benefits, Limitations, and Harms. CTC provides a time-efficient procedure with minimal invasiveness. No sedation or recovery time is required, nor is a chaperone needed to provide transportation after the procedure. Time permitting, patients can return to work on the same day. However, some limitations to CTC exist. At this time, reimbursement for screening CTC is very limited, although 47 states now offer Medicare reimbursement for diagnostic CTC where the clinical indication is limited to incomplete OC. ${ }^{173}$ However, because reimbursement for screening still is uncommon, the current professional capacity to deliver CTC also is limited, although capacity is expected to increase when third-party payers begin providing reimbursement for screening.

As an "imaging-only," nontherapeutic evaluation, patients with polyps of significant size will require therapeutic CSPY for subsequent polypectomy. CTC requires the same full cathartic bowel preparation and restricted diet as OC, which may decrease patient adherence. However, with this approach, same-day polypectomy can be offered without the need for an additional bowel preparation, although this convenience for patients requires careful coordination between radiology and gastroenterology departments. ${ }^{174}$

CTC is similar to endoscopy and DCBE with respect to the quality of interpretation being highly operator dependent, and thus initiatives toward training and certification are important. Detection of flat lesions has been variable, ranging from sensitivities of $13 \%$ to $65 \%$ in early CTC studies ${ }^{175}$ to $80 \%$ when using multidetector CT and combined 3D-2D polyp detection. ${ }^{176}$ However, debate continues over the prevalence and significance of flat colorectal lesions. ${ }^{177-179}$

The accuracy of CTC is influenced by lesion size, and the sensitivity and specificity of CTC improves with polyp size. The accuracy of CTC in measuring polyp size is of particular importance since accurate size estimation is critical for appropriate patient management and for minimizing the false-positive rate. While earlier studies using rudimentary software applied to wide-slice thicknesses and 2D images showed poor concordance with prefixation polyp size, ${ }^{180}$ modern CT technology producing $3 \mathrm{D}$ images results in more accurate size estimates. ${ }^{181-183}$ The ability to ensure consistent polyp size measurements during examinations is a high priority for quality-assurance initiatives since it will influence referrals for polypectomy. Pickhardt et al showed that specificity (when polyps were matched for size) was $97.4 \%$ for lesions _ $1 \mathrm{~cm}$ but declines to $84.5 \%$ for all lesions to all lesions -6mm. ${ }^{167}$ The incremental increase in the falsepositive rate associated with polyps between 6 to $8 \mathrm{~mm}$ could add significantly to the cost of screening, and thus it will be important to monitor sensitivity and specificity in the clinical setting and identify strategies to improve specificity without diminishing sensitivity. There is controversy over the long-term potential harms associated with radiation dose effects from $\mathrm{CT}$ examinations. One aspect of this controversy relates to risk-estimation models, and the other pertains to the long-term risk of cancer from single and repeated medical imaging exposures. ${ }^{184,185}$ While current estimates of the potential cancer risk related to low-dose radiation exposures during medical procedures derive from linear nonthreshold models based on long-term outcomes in survivors of acute radiation doses from atomic weapons, there is disagreement over whether this model truly is applicable to periodic exposures from medical imaging. ${ }^{186}$ In a recent position statement issued by the Health Physics Society, the health effects of low-dose radiation exposure (defined as below 50 to $100 \mathrm{mSv}-\mathrm{a}$ threshold many times higher than typical CTC levels) were considered to be "either too small to be observed or are nonexistent." 187 Nevertheless, although this risk may be theoretical, there is a growing concern that more individuals are receiving multiple diagnostic evaluations with ionizing radiation over a lifetime and that for some individuals the doses over a lifetime can reach levels that are sufficiently high to be of concern. It is important to put these issues into context with respect to screening with CTC. Using the linear, no-threshold radiation-risk estimate, a CTC examination in a 50-year-old individual with an estimated organ dose to the colon of 7 to $13 \mathrm{mSv}$ ( $65 \mathrm{mAs}$ ) is estimated to add an additional $0.044 \%$ to the lifetime risk of colon cancer. ${ }^{188}$ Because organ radiosensitivity declines with in- 
creasing age, this organ dose is halved for the same examination taking place at age 70 years. In this same evaluation, the additional lifetime risk of cancer in any site associated with a single CTC examination at age 50 years was $0.14 \%$, although the authors stated with optimized techniques this risk could be reduced by a factor of 5- to10-fold. More efficient dose protocols using $50 \mathrm{mAs}$ on 4DCT, similar to the ACR-defined protocols, have demonstrated decreased estimated organ dose ranges of 5 to $8 \mathrm{mSv} .{ }^{189}$ While acknowledging there is uncertainty about potential harms from single or multiple CTC screening examinations, current ACR quality metrics for CTC define low-dose parameters as a best practice for minimizing risk to patients. ${ }^{190}$ Since CTC is a minimally invasive test, the risk for colonic perforation during screening is extremely low. In the collective experience of the International Working Group on Virtual Colonoscopy, there were no cases of perforation in over 11,000 screening CTC examinations, and out of nearly 22,000 total CTC examinations (screening and diagnostic), there was only one symptomatic perforation, corresponding to a symptomatic perforation rate of $0.005 \% .{ }^{191}$ Some studies of symptomatic patients, however, have reported higher perforation rates, ranging from $0.03 \%$ ( 1 in 3,400 patients) to $0.06 \%$ ( 1 in 1,700 patients). ${ }^{192,193}$ Colonic distention with lowpressure carbon dioxide delivery may be safer than insufflation of room air. ${ }^{191}$ Rates of perforation are part of the quality metrics being collected by the ACR. Because CTC produces an image not only of the colon but also the upper and lower abdomen, there is a chance that incidental extracolonic findings will be observed. Although the overall rates of extracolonic findings have been reported to range from $15 \%$ to $69 \%$, the incidence of clinically significant extracolonic findings at CTC has ranged from $4.5 \%$ to $11 \%$ in various patient cohorts. ${ }^{194-197}$ In an asymptomatic screening population, the incidence of unsuspected but potentially important extracolonic findings is approximately $4.5 \%$, but findings of minimal or moderate potential clinical significance, such as cholelithiasis (6\%) and nephrolithiasis (8\%), are more common. ${ }^{197}$ While there are potential benefits from serendipitous findings, there also are associated risks and costs that need to be considered when these findings are false positives. These include further radiologic imaging and, thus, added organ dose, potential for adverse outcomes associated with tissue sampling for abnormalities that are not resolved with additional imaging, as well as the direct and indirect costs to the patient. The implementation of structured reporting of extracolonic findings and monitoring trends in subsequent diagnostic workups and adherence with quality metrics are being evaluated through the National Radiology Data Registry (NRDR), the ACR's national data warehouse.

Quality Assurance. Similar to the call to action for measuring quality of CSPY, ${ }^{198}$ the implementation of CTC will require quality metrics to be defined and im- plemented in clinical practice. Quality of CTC examinations will depend on (1) proper bowel preparation; (2) adequate insufflation of the colon and appropriate use of CTC technique parameters at image acquisition; (3) adequate training of the interpreting physician in the use of 2D and 3D image display techniques; and (4) documentation of clinically significant colonic and extracolonic lesions to referring physicians. In 2005, the ACR Practice Guideline for the Performance of Computed Tomography (CT) Colonography in Adults was published, encompassing the techniques, quality control, clinical uses, training, and communication of results for CTC. ${ }^{190}$ An update of these guidelines is planned following publication of the results of the ACRIN CTC screening trial. In 2006, the ACR Colon Cancer Committee outlined practice-based quality metrics for CTC, encompassing process measures of CTC technique and image quality; patient preparation; and outcomes measures such as rates of true positives, colonic perforation, and incidence of extracolonic findings. These quality metrics are to begin a pilot phase in late 2007, with data entry in the National Radiology Data Register (NRDR) database. The ACR has begun construction of an interactive hands-on training facility for CTC and will begin training courses in early 2008. A process for individual certification and proficiency is being evaluated.

CTC-Other Issues. Standardization of the evolving technology and consensus related to the reporting of findings will be essential for effective implementation of CTC screening. A consensus statement of a standardized reporting structure for CTC findings was recently published, modeled after the Breast Imaging Reporting and Data System's (BI-RADS) reporting of mammography. ${ }^{199}$ This reporting structure, termed the "CT Colonography Reporting and Data System (C-RADS)," describes how to report lesion size, morphology, and location, with a summary category score per patient.

The management of CTC findings is an important part of a CTC screening program. At this time, there is consensus that all patients with one or more polyps $\geq 10 \mathrm{~mm}$ or 3 or more polyps $\geq 6 \mathrm{~mm}$ should be referred for CSPY.77,200 The management of patients with fewer polyps $(<3)$ in which the largest polyp is 6 to $9 \mathrm{~mm}$ remains controversial. Such polyps are routinely removed if found at OC because of the opportunity and the risk, albeit low, of advanced neoplasia. However, in studies that have been limited to screening cohorts, among individuals whose largest polyp is 6 to $9 \mathrm{~mm}$ in size, the prevalence of advanced features tends to be low (3.4\% to 6.6\%). ${ }^{201,202}$ At this time, there is ongoing research using CTC surveillance to evaluate the natural history of polyps in this size range. Based on expert consensus and until further evidence is available to provide additional guidance, a reasonable approach at this time for patients with 6- to 9-mm polyps identified on CTC is to offer therapeutic CSPY. Patients who decline referral to CSPY or who are 
not good candidates for CSPY should be offered surveillance with CTC.

Optimal management of patients whose largest polyp is $<6 \mathrm{~mm}$ detected on CTC is uncertain. Experts from the American Gastroenterological Association, the American College of Gastroenterology, and the ACR have reported a range of policies on how to handle these lesions. ${ }^{190,203,204}$ There is general agreement that the risk of advanced features in patients whose largest polyp is $\leq 5$ $\mathrm{mm}$ is very low. In a recent study that is able to provide this estimate in a screening cohort, the prevalence of advanced neoplasia in patients whose largest polyp was $\leq 5 \mathrm{~mm}$ was $1.7 \%$ (D.A.L., personal communication, December 14, 2007). ${ }^{202}$ At this time, there is a pressing need for multidisciplinary consensus on the reporting and clinical management of patients whose largest polyp is $<6 \mathrm{~mm}$.

CTC-Conclusions and Recommendations. In terms of detection of colon cancer and advanced neoplasia, which is the primary goal of screening for CRC and adenomatous polyps, recent data suggest CTC is comparable to OC for the detection of cancer and polyps of significant size when state-of-the-art techniques are applied.

In previous assessments of the performance of CTC, the ACS concluded that data were insufficient to recommend screening with CTC for average-risk individuals. ${ }^{19}$ Based on the accumulation of evidence since that time, the expert panel concludes that there are sufficient data to include CTC as an acceptable option for CRC screening.

Screening of average-risk adults with CTC should commence at age 50 years. The interval for repeat exams after a negative CTC has not been studied and is uncertain. However, if current studies confirm the previously reported high sensitivity for detection of cancer and of polyps $\geq 6 \mathrm{~mm}$, it would be reasonable to repeat exams every 5 years if the initial CTC is negative for significant polyps until further studies are completed and are able to provide additional guidance. Until there is more research on the safety of observation, patients whose largest polyp is $6 \mathrm{~mm}$ or greater should be offered CSPY. CTC surveillance could be offered to those patients who would benefit from screening but either decline CSPY or are not good candidates for CSPY for one or more reasons. However, if CSPY is contraindicated because the patient is not likely to benefit from screening due to life-limiting comorbidity, then neither CTC nor any other CRC screening test would be appropriate.

\section{Conclusion}

There is compelling evidence to support screening average-risk individuals over age 50 years to detect and prevent CRC. Screening of average-risk individuals can reduce CRC mortality by detecting cancer at an early, curable stage and by detecting and removing clinically significant adenomas. No CRC screening test is perfect, either for cancer detection or adenoma detection. Each test has unique advantages, each has been shown to be cost-effective, ${ }^{205-208}$ and each has associated limitations and risks. Patient preferences and availability of resources play an important role in the selection of screening tests. In this update of the guidelines for CRC screening, we have placed an emphasis on the value of preventing CRC, sought to address the importance of test sensitivity in the presence of low rates of programmatic screening, and attempted to provide improved guidance about test characteristics and quality issues to referring clinicians. Ideally, screening should be supported in a programmatic fashion that begins with risk stratification and the results from an initial test and continues through proper follow-up based on findings. The effectiveness of any single test or combination of tests depends on high rates of programmatic adherence and quality.

Based on differing incidence rates and observations of different patterns of polyp and cancer distribution in certain subsets of patients (ie, the elderly, women, ethnic minorities, etc), some experts have suggested that these groups may require different screening recommendations. ${ }^{209,210}$ The expert panel reviewed and discussed the evidence and rationale for and against including different screening recommendations in this update for various demographic subgroups that have been shown to be at somewhat higher or lower than average risk for disease or proximal lesions. After some consideration, this issue was postponed for further consideration at a later time for a number of reasons, although principally because (1) there are no current data to indicate that CRC incidence and mortality in these groups would be positively impacted by tailored screening recommendations; and (2) screening rates among all groups remain low under existing guidelines, and providing different (and, in some cases, more limited) screening options has the potential to increase confusion, complexity, and workload and thus might add additional barriers to screening that would affect all groups. This is an area of research that the 3 organizations' guidelines committees will continue to monitor closely.

In this update of the CRC screening guidelines, we have focused on screening in average-risk adults and have not reviewed recent literature on CRC screening or surveillance for individuals at increased and high risk. Individuals at increased risk due to a history of adenomatous polyps; a personal history of curative-intent resection of CRC; a family history of either CRC or colorectal adenomas diagnosed in a first-degree relative before age 60 years; or high risk due to a history of inflammatory bowel disease of significant duration or the presence of one of 2 hereditary syndromes should continue to follow recommendations issued previously by the ACS or USMSTF. ${ }^{18,24}$ These recommendations are summarized in Table 3.

There appears to be a clear need for institutionally based quality assurance programs to improve the quality 
Table 3. Guidelines for Screening and Surveillance for the Early Detection of Colorectal Adenomas and Cancer in Individuals at Increased Risk or at High Risk

\begin{tabular}{|c|c|c|c|}
\hline Risk category & Age to begin & Recommendation & Comment \\
\hline \multicolumn{4}{|c|}{ Increased Risk-Patients with History of Polyps at Prior Colonoscopy } \\
\hline $\begin{array}{l}\text { Patients with small } \\
\text { rectal hyperplastic } \\
\text { polyps }^{26}\end{array}$ & - & $\begin{array}{l}\text { Colonoscopy or other } \\
\text { screening options at } \\
\text { intervals } \\
\text { recommended for } \\
\text { average-risk } \\
\text { individuals }\end{array}$ & $\begin{array}{l}\text { An exception is patients with a hyperplastic } \\
\text { polyposis syndrome. They are at } \\
\text { increased risk for adenomas and } \\
\text { colorectal cancer and need to be } \\
\text { identified for more intensive follow-up. }\end{array}$ \\
\hline $\begin{array}{l}\text { Patients with } 1 \text { or } 2 \\
\text { small tubular } \\
\text { adenomas with low- } \\
\text { grade dysplasia } 26\end{array}$ & $\begin{array}{l}5 \text { to } 10 \text { years after the } \\
\text { initial polypectomy }\end{array}$ & Colonoscopy & $\begin{array}{l}\text { The precise timing within this interval } \\
\text { should be based on other clinical factors } \\
\text { (such as prior colonoscopy findings, } \\
\text { family history, and the preferences of the } \\
\text { patient and judgment of the physician). }\end{array}$ \\
\hline $\begin{array}{l}\text { Patients with } 3 \text { to } 10 \\
\text { adenomas, or } 1 \\
\text { adenoma }>1 \mathrm{~cm} \text {, or } \\
\text { any adenoma with } \\
\text { villous features or } \\
\text { high-grade } \\
\text { dysplasia } 26\end{array}$ & $\begin{array}{l}3 \text { years after the initial } \\
\text { polypectomy }\end{array}$ & Colonoscopy & $\begin{array}{l}\text { Adenomas must have been completely } \\
\text { removed. If the follow-up colonoscopy is } \\
\text { normal or shows only } 1 \text { or } 2 \text { small } \\
\text { tubular adenomas with low-grade } \\
\text { dysplasia, then the interval for the } \\
\text { subsequent examination should be } 5 \\
\text { years. }\end{array}$ \\
\hline $\begin{array}{l}\text { Patients with }>10 \\
\text { adenomas on a } \\
\text { single examination } 26\end{array}$ & $\begin{array}{l}<3 \text { years after the initial } \\
\text { polypectomy }\end{array}$ & Colonoscopy & $\begin{array}{l}\text { Consider the possibility of an underlying } \\
\text { familial syndrome. }\end{array}$ \\
\hline $\begin{array}{l}\text { Patients with sessile } \\
\text { adenomas that are } \\
\text { removed } \\
\text { piecemeal }^{26}\end{array}$ & $\begin{array}{l}2 \text { to } 6 \text { months to verify } \\
\text { complete removal }\end{array}$ & Colonoscopy & $\begin{array}{l}\text { Once complete removal has been } \\
\text { established, subsequent surveillance } \\
\text { needs to be individualized based on the } \\
\text { endoscopist's judgment. Completeness } \\
\text { of removal should be based on both } \\
\text { endoscopic and pathologic assessments. }\end{array}$ \\
\hline \multicolumn{4}{|c|}{ Increased Risk-Patients with Colorectal Cancer } \\
\hline $\begin{array}{l}\text { Patients with colon } \\
\text { and rectal cancer } \\
\text { should undergo high- } \\
\text { quality perioperative } \\
\text { clearing } 25\end{array}$ & $\begin{array}{l}3 \text { to } 6 \text { months after } \\
\text { cancer resection, if no } \\
\text { unresectable metastases } \\
\text { are found during surgery; } \\
\text { alternatively, colonoscopy } \\
\text { can be performed } \\
\text { intraoperatively. }\end{array}$ & Colonoscopy & $\begin{array}{l}\text { In the case of nonobstructing tumors, this } \\
\text { can be done by preoperative } \\
\text { colonoscopy. In the case of obstructing } \\
\text { colon cancers, CTC with intravenous } \\
\text { contrast or DCBE can be used to detect } \\
\text { neoplasms in the proximal colon. }\end{array}$ \\
\hline $\begin{array}{l}\text { Patients undergoing } \\
\text { curative resection } \\
\text { for colon or rectal } \\
\text { cancer }^{23}\end{array}$ & $\begin{array}{l}1 \text { year after the resection } \\
\text { (or } 1 \text { year following the } \\
\text { performance of the } \\
\text { colonoscopy that was } \\
\text { performed to clear the } \\
\text { colon of synchronous } \\
\text { disease) }\end{array}$ & Colonoscopy & $\begin{array}{l}\text { This colonoscopy at } 1 \text { year is in addition to } \\
\text { the perioperative colonoscopy for } \\
\text { synchronous tumors. If the examination } \\
\text { performed at } 1 \text { year is normal, then the } \\
\text { interval before the next subsequent } \\
\text { examination should be } 3 \text { years. If that } \\
\text { colonoscopy is normal, then the interval } \\
\text { before the next subsequent examination } \\
\text { should be } 5 \text { years. Following the } \\
\text { examination at } 1 \text { year, the intervals } \\
\text { before subsequent examinations may be } \\
\text { shortened if there is evidence of HNPCC } \\
\text { or if adenoma findings warrant earlier } \\
\text { colonoscopy. Periodic examination of the } \\
\text { rectum for the purpose of identifying } \\
\text { local recurrence, usually performed at } 3- \\
\text { to } 6 \text {-month intervals for the first } 2 \text { or } 3 \\
\text { years, may be considered after low } \\
\text { anterior resection of rectal cancer. }\end{array}$ \\
\hline \multicolumn{4}{|c|}{ Increased Risk-Patients with a Family History } \\
\hline $\begin{array}{l}\text { Either colorectal } \\
\text { cancer or } \\
\text { adenomatous polyps } \\
\text { in a first-degree } \\
\text { relative before age } \\
60 \text { years or in } 2 \text { or } \\
\text { more first-degree } \\
\text { relatives at any age } 24\end{array}$ & $\begin{array}{l}\text { Age } 40 \text { years, or } 10 \text { years } \\
\text { before the youngest } \\
\text { case in the immediate } \\
\text { family }\end{array}$ & Colonoscopy & Every 5 years \\
\hline
\end{tabular}

Patients with 1 or 2

small tubular

adenomas with low-

Patients with 3 to 10

adenomas, or 1

high-grade

dysplasia

adenomas on a

single examination ${ }^{26}$

adenomas that are

removed

piecemeal $^{26}$

\section{Colorectal Cancer}

should undergo high-

quality perioperative

clearing ${ }^{25}$

Patients undergoing

curative resection

for colon or rectal

cancer $^{23}$ are found during surgery; alternatively, colonoscopy can be performed

year after the resection

(or 1 year following the pynchronous (ase)

\section{ncreased Risk-Patients with a Family History}

cancer or

adenomatous polyps

60 years or in 2 or

relatives at any age ${ }^{24}$ colorectal cancer and need to be

The precise timing within this interval should be based on other clinical factors family history, and the preferences of the patient and judgment of the physician).

removed. If the follow-up colonoscopy is normal or shows only 1 or 2 small ubular adenomas with low-grade splasia, then the interval for the years.

Consider the possibility of an underlying

nce complete removal has been stablished, subsequent surveillance of removal should be based on both

tumors, this colonoscopy. In the case of obstructing colon cancers, CTC with intravenous contrast or DCBE can be used to detect

is colonoscopy at 1 year is in addition to the perioperative colonoscopy for interval before the next subsequent examination should be 3 years. If that conoscopy is normal, then the interval should be 5 years. Following the examination at 1 year, the intervals or if adenoma findings warrant earlier colonoscopy. Periodic examination of the for the purpose of identifying years, may be considered after low

Every 5 years 
Table 3 (continued).

\begin{tabular}{|c|c|c|c|}
\hline Risk category & Age to begin & Recommendation & Comment \\
\hline $\begin{array}{l}\text { Either colorectal } \\
\text { cancer or } \\
\text { adenomatous polyps } \\
\text { in a first-degree } \\
\text { relative age } 60 \text { or } \\
\text { older or in } 2 \text { second- } \\
\text { degree relatives with } \\
\text { colorectal cancer } 24\end{array}$ & Age 40 years & $\begin{array}{l}\text { Screening options at } \\
\text { intervals } \\
\text { recommended for } \\
\text { average-risk } \\
\text { individuals }\end{array}$ & $\begin{array}{l}\text { Screening should be at an earlier age, but } \\
\text { individuals may choose to be screened } \\
\text { with any recommended form of testing. }\end{array}$ \\
\hline \multicolumn{4}{|l|}{ High Risk } \\
\hline $\begin{array}{l}\text { Genetic diagnosis of } \\
\text { FAP or suspected } \\
\text { FAP without genetic } \\
\text { testing evidence } 24\end{array}$ & Age 10 to 12 years & $\begin{array}{l}\text { Annual FSIG to } \\
\text { determine if the } \\
\text { individual is } \\
\text { expressing the } \\
\text { genetic abnormality } \\
\text { and counseling to } \\
\text { consider genetic } \\
\text { testing }\end{array}$ & $\begin{array}{l}\text { If the genetic test is positive, colectomy } \\
\text { should be considered. }\end{array}$ \\
\hline $\begin{array}{l}\text { Genetic or clinical } \\
\text { diagnosis of HNPCC } \\
\text { or individuals at } \\
\text { increased risk of } \\
\text { HNPCC }^{24}\end{array}$ & $\begin{array}{l}\text { Age } 20 \text { to } 25 \text { years, or } 10 \\
\text { years before the } \\
\text { youngest case in the } \\
\text { immediate family }\end{array}$ & $\begin{array}{l}\text { Colonoscopy every } 1 \text { to } \\
2 \text { years and } \\
\text { counseling to } \\
\text { consider genetic } \\
\text { testing }\end{array}$ & $\begin{array}{l}\text { Genetic testing for HNPCC should be } \\
\text { offered to first-degree relatives of } \\
\text { persons with a known inherited MMR } \\
\text { gene mutation. It should also be offered } \\
\text { when the family mutation is not already } \\
\text { known, but } 1 \text { of the first } 3 \text { of the } \\
\text { modified Bethesda criteria is present }\end{array}$ \\
\hline $\begin{array}{l}\text { Inflammatory bowel } \\
\text { disease, }{ }^{24} \text { chronic } \\
\text { ulcerative colitis, } \\
\text { and Crohn's colitis }\end{array}$ & $\begin{array}{l}\text { Cancer risk begins to be } \\
\text { significant } 8 \text { years after } \\
\text { the onset of pancolitis } \\
\text { or } 12 \text { to } 15 \text { years after } \\
\text { the onset of left-sided } \\
\text { colitis }\end{array}$ & $\begin{array}{l}\text { Colonoscopy with } \\
\text { biopsies for dysplasia }\end{array}$ & $\begin{array}{l}\text { Every } 1 \text { to } 2 \text { years; these patients are best } \\
\text { referred to a center with experience in } \\
\text { the surveillance and management of } \\
\text { inflammatory bowel disease. }\end{array}$ \\
\hline
\end{tabular}

CRC, colorectal cancer; CSPY, colonoscopy; CTC, computed tomographic colonography; DCBE, double-contrast barium enema; FAP, familial adenomatous polyposis; FSIG, flexible sigmoidoscopy; HNPCC, hereditary nonpolyposis colon cancer; MMR, mismatch repair.

of CRC screening. This guideline update emphasizes issues for quality assurance across colorectal screening modalities, spanning training requirements, optimal techniques to complete examination, screening intervals, and appropriate recommendations for follow-up. In contrast, cost-effectiveness is not specifically discussed in this document, based on the numerous complexities of adequately addressing this topic, including understanding real costs in different environments, differences in test performance and interpretation, and wide variability of screening intervals in different settings. It is hoped that compliance with improvements in quality assurance will both improve quality and promote cost-effectiveness.

Clearly, better definition of the target lesion of clinical importance is needed across modalities. As new technologies evolve that detect but do not remove polyps, multidisciplinary consensus is needed to best manage a patient programmatically for follow-up polypectomy versus surveillance intervals. Although there are some ongoing studies of the natural history of small polyps, evidencebased data will probably take 10 to 20 years to meaningfully translate into clinical practice recommendations. In this interim, the current recommendations try to address these issues with expert consensus based on existing data.
Multidisciplinary groups, such as the National Colorectal Cancer Roundtable, may be able to serve as an effective forum for the development of a consensus across specialties about the reporting and follow-up of small polyps.

In conclusion, it is our hope that these new recommendations will facilitate increased rates of CRC screening and that referring clinicians find these new guidelines ease some of the challenges they have experienced in promoting CRC screening to their patients.

\section{References}

1. Jemal A, Siegel R,Ward E, et al. Cancer statistics, 2008. CA Cancer J Clin 2008:58:71-96.

2. Ries L, Melbert D, Krapcho M, et al. (eds). SEER Cancer Statistics Review, 1975-2004. Bethesda, MD: National Cancer Institute; 2007.

3. Espey DK,Wu XC, Swan J, et al. Annual report to the nation on the status of cancer, 1975-2004, featuring cancer in American Indians and Alaska Natives. Cancer 2007;110:21192152.

4. Selby JV, Friedman GD, Quesenberry CP Jr, Weiss NS. A casecontrol study of screening sigmoidoscopy and mortality from colorectal cancer. N Engl J Med 1992;326:653-657.

5. Hardcastle JD, Chamberlain JO, Robinson MH, et al. Randomised controlled trial of faecal-occultblood screening for colorectal cancer. Lancet 1996;348:1472-1477. 
6. Kronborg $\mathrm{O}$,Fenger $\mathrm{C}$,Olsen J,et al. Randomised study of screening for colorectal cancer with faecaloccult- blood test. Lancet 1996;348:1467-1471.

7. Mandel JS, Church TR, Bond JH, et al. The effect of fecal occult-blood screening on the incidence of colorectal cancer.N Engl J Med 2000;343: 1603-1607.

8. Meissner HI, Breen N, Klabunde CN,Vernon SW. Patterns of colorectal cancer screening uptake among men and women in the United States. Cancer Epidemiol Biomarkers Prev 2006;15: 389-394.

9. Smith RA, Cokkinides V, Eyre HJ. Cancer screening in the United States, 2007: a review of current guidelines, practices, and prospects. CA Cancer J Clin 2007;57:90-104.

10. O'Brien MJ,Winawer SJ, Zauber AG, et al. The National Polyp Study. Patient and polyp characteristics associated with highgrade dysplasia in colorectal adenomas. Gastroenterology 1990;98:371-379.

11. Bond JH. Colon polyps and cancer. Endoscopy 2003;35:27-35.

12. Winawer SJ, Fletcher RH, Miller L, et al. Colorectal cancer screening: clinical guidelines and rationale. Gastroenterology 1997;112:594-642.

13. Winawer SJ. Natural history of colorectal cancer. Am J Med 1999;106:3S-6S.

14. Lieberman DA,Weiss DG. One-time screening for colorectal cancer with combined fecal occult-blood testing and examination of the distal colon. N Engl J Med 2001;345:555-560.

15. Eddy D. ACS report on the cancer-related health checkup. CA Cancer J Clin 1980;30:193-240.

16. Levin B, Murphy GP. Revision in American Cancer Society recommendations for the early detection of colorectal cancer. CA Cancer J Clin 1992;42:296-299.

17. Byers T, Levin B, Rothenberger D, et al. American Cancer Society guidelines for screening and surveillance for early detection of colorectal polyps and cancer: update 1997. American Cancer Society Detection and Treatment Advisory Group on Colorectal Cancer. CA Cancer J Clin 1997;47:154-160.

18. Smith RA, von Eschenbach AC,Wender R, et al. American Cancer Society guidelines for the early detection of cancer: update of early detection guidelines for prostate, colorectal, and endometrial cancers. Also: update 2001-testing for early lung cancer detection. CA Cancer J Clin 2001; 51:38-75.

19. Levin B, Brooks D, Smith RA, Stone A. Emerging technologies in screening for colorectal cancer: CT colonography, immunochemical fecal occult blood tests, and stool screening using molecular markers. CA Cancer J Clin 2003;53:44-55.

20. US Preventive Services Task Force. Guide to Clinical Preventive Services. 2nd ed. Baltimore, MD: Williams \& Wilkins; 1996.

21. US Preventive Services Task Force. Screening for colorectal cancer: recommendation and rationale. Ann Intern Med 2002; 137:129-131.

22. Glick SN. Comparison of colonoscopy and double-contrast barium enema. N Engl J Med 2000;343:1728.

23. Heiken JP,Bree RL,Foley WD, et al. Colorectal cancer screening. American College of Radiology (ACR) Appropriateness Criteria. Reston, VA: American College of Radiology; 2006.

24. Winawer S, Fletcher R, Rex D, et al. Colorectal cancer screening and surveillance: clinical guidelines and rationale-update based on new evidence. Gastroenterology 2003;124:544-560.

25. Rex DK,Kahi CJ,Levin B, et al. Guidelines for colonoscopy surveillance after cancer resection: a consensus update by the American Cancer Society and the US Multi-Society Task Force on Colorectal Cancer. Gastroenterology 2006;130:1865-1871.

26. Winawer SJ, Zauber AG, Fletcher RH, et al. Guidelines for colonoscopy surveillance after polypectomy: a consensus update by the US Multi- Society Task Force on Colorectal Cancer and the American Cancer Society. CA Cancer J Clin 2006;56: 143-159.
27. Wee CC, McCarthy EP, Phillips RS. Factors associated with colon cancer screening: the role of patient factors and physician counseling. Prev Med 2005;41:23-29.

28. Vernon SW. Participation in colorectal cancer screening: a review. J Natl Cancer Inst 1997;89:1406-1422.

29. Schroy PC 3rd, Heeren TC. Patient perceptions of stool-based DNA testing for colorectal cancer screening. Am J Prev Med 2005;28:208-214.

30. Tangka FK, Molinari NA, Chattopadhyay SK, Seeff LC. Market for colorectal cancer screening by endoscopy in the United States. Am J Prev Med 2005;29:54-60.

31. Lafata JE, Divine G, Moon C, Williams LK. Patient-physician colorectal cancer screening discussions and screening use. Am J Prev Med 2006;31:202-209.

32. Pignone M, Rich M, Teutsch SM, et al. Screening for colorectal cancer in adults at average risk: a summary of the evidence for the US Preventive Services Task Force. Ann Intern Med 2002; 137:132-141.

33. Mandel JS, Bond JH, Church TR, et al. Reducing mortality from colorectal cancer by screening for fecal occult blood. Minnesota Colon Cancer Control Study. N Engl J Med 1993;328:13651371.

34. Wilson JMG, Junger G. Principles and Practice of Screening for Disease. Geneva, Switzerland: World Health Organization; 1968.

35. Smith RA. Screening fundamentals. J Natl Cancer Inst Monogr 1997;22:15-19.

36. Shapiro SScreening for secondary prevention of disease, in Armenian HK, Shapiro S (eds).Epidemiology and Health Services.18319981940xford University PressNew York, NY 206.

37. Imperiale TF, Ransohoff DF, Itzkowitz SH, et al. Fecal DNA versus fecal occult blood for colorectal- cancer screening in an average-risk population. N Engl J Med 2004;351:2704-2714.

38. Collins JF, Lieberman DA, Durbin TE,Weiss DG. Accuracy of screening for fecal occult blood on a single stool sample obtained by digital rectal examination: a comparison with recommended sampling practice. Ann Intern Med 2005;142:81-85.

39. Nadel MR, Shapiro JA, Klabunde CN, et al. A national survey of primary care physicians' methods for screening for fecal occult blood. Ann Intern Med 2005;142:86-94.

40. Sox HC. Office-based testing for fecal occult blood: do only in case of emergency. Ann Intern Med 2005;142:146-148.

41. Myers RE, Balshem AM, Wolf TA, et al. Adherence to continuous screening for colorectal neoplasia. Med Care 1993;31:508519.

42. Engelman KK, Ellerbeck EF, Ahluwalia JS, et al. Fecal occult blood test use by Kansas medicare beneficiaries. Prev Med 2001;33:622-626.

43. Schattner A, Gilad A. Primary care physicians' awareness and implementation of screening guidelines for colorectal cancer. Prev Med 2002;35:447-452.

44. American College of Radiology Imaging Network. ACRIN Protocol 6656. Computerized Tomographic Colonography: Performance Evaluation in a Multicenter Setting. Available at: http://www.acrin.org/TabID/146/Default.aspx. Accessed July 1, 2007.

45. Young GP, St John DJ. Selecting an occult blood test for use as a screening tool for large bowel cancer, in Rozen P, Reich CB,Winawer SJ (eds). Frontiers of Gastrointestinal Research. Advances in Large Bowel Cancer: Policy,Prevention, Research and Treatment. Basel, Switzerland: Karger; 1991:135-156.

46. Ransohoff DF, Lang CA. Screening for colorectal cancer with the fecal occult blood test: a background paper. American College of Physicians. Ann Intern Med 1997;126:811-822.

47. Allison JE,Tekawa IS, Ransom LJ, Adrain AL. A comparison of fecal occult-blood tests for colorectal- cancer screening. N Engl J Med 1996;334:155-159. 
48. Simon JB. Occult blood screening for colorectal carcinoma: a critical review. Gastroenterology 1985;88:820-837.

49. Allison JE, Sakoda LC, Levin TR, et al. Screening for colorectal neoplasms with new fecal occult blood tests: update on performance characteristics. J Natl Cancer Inst 2007;99:14621470.

50. Sinatra MA, Young GP, St John DJ, et al. A study of laboratory based faecal occult blood testing in Melbourne, Australia. The Faecal Occult Blood Testing Study Group. J Gastroenterol Hepatol 1998;13:396-400.

51. Adams EC, Layman KM. Immunochemical confirmation of gastrointestinal bleeding. Ann Clin Lab Sci 1974;4:343-349.

52. Newman L. Medicare coverage group assesses effectiveness of new technologies. J Natl Cancer Inst 2001;93:805-806.

53. Caligiore P, Macrae FA, St John DJ, et al. Peroxidase levels in food: relevance to colorectal cancer screening. Am J Clin Nutr 1982;35:1487-1489.

54. Gopalswamy N, Stelling HP, Markert RJ, et al. A comparative study of eight fecal occult blood tests and HemoQuant in patients in whom colonoscopy is indicated. Arch Fam Med 1994; 3:1043-1048.

55. Greenberg PD, Bertario L, Gnauck R, et al. A prospective multicenter evaluation of new fecal occult blood tests in patients undergoing colonoscopy. Am J Gastroenterol 2000;95:13311338.

56. Wong $\mathrm{BC}$,Wong $\mathrm{WM}$, Cheung $\mathrm{KL}$, et al. A sensitive guaiac faecal occult blood test is less useful than an immunochemical test for colorectal cancer screening in a Chinese population. Aliment Pharmacol Ther 2003;18:941-946.

57. Smith A, Young GP, Cole SR, Bampton P. Comparison of a brush-sampling fecal immunochemical test for hemoglobin with a sensitive guaiac- based fecal occult blood test in detection of colorectal neoplasia. Cancer 2006;107:2152-2159.

58. Levi Z, Rozen P, Hazazi R, et al. A quantitative immunochemical fecal occult blood test for colorectal neoplasia. Ann Intern Med 2007;146:244-255.

59. Morikawa T, Kato J, Yamaji Y, et al. A comparison of the immunochemical fecal occult blood test and total colonoscopy in the asymptomatic population. Gastroenterology 2005;129:422428.

60. Cole SR,Young GP,Esterman A, et al. A randomised trial of the impact of new faecal haemoglobin test technologies on population participation in screening for colorectal cancer. J Med Screen 2003;10:117-122.

61. Nakama H, Yamamoto M, Kamijo N, et al. Colonoscopic evaluation of immunochemical fecal occult blood test for detection of colorectal neoplasia. Hepatogastroenterology 1999;46:228231.

62. Sidransky D, Tokino T, Hamilton SR, et al. Identification of ras oncogene mutations in the stool of patients with curable colorectal tumors. Science 1992;256:102-105.

63. Whitney D, Skoletsky J, Moore K, et al. Enhanced retrieval of DNA from human fecal samples results in improved performance of colorectal cancer screening test. J Mol Diagn 2004; 6:386-395.

64. Olson J,Whitney DH, Durkee K, Shuber AP. DNA stabilization is critical for maximizing performance of fecal DNA-based colorectal cancer tests. Diagn Mol Pathol 2005;14:183-191.

65. Ahlquist DA, Skoletsky JE,Boynton KA, et al. Colorectal cancer screening by detection of altered human DNA in stool: feasibility of a multitarget assay panel. Gastroenterology 2000;119: 1219-1227.

66. Calistri D, Rengucci C, Bocchini R, et al. Fecal multiple molecular tests to detect colorectal cancer in stool. Clin Gastroenterol Hepatol 2003; 1:377-383.

67. Tagore KS, Lawson MJ, Yucaitis JA, et al. Sensitivity and specificity of a stool DNA multitarget assay panel for the detection of advanced colorectal neoplasia. Clin Colorectal Cancer 2003;3:47-53.

68. Brand RE, Ross ME, Shuber AP. Reproducibility of a multitarget stool-based DNA assay for colorectal cancer detection. Am J Gastroenterol 2004;99:1338-1341.

69. Syngal S, Stoffel E, Chung D, et al. Detection of stool DNA mutations before and after treatment of colorectal neoplasia. Cancer 2006;106:277-283.

70. Itzkowitz SH, Jandorf L, Brand R, et al. Improved fecal DNA test for colorectal cancer screening. Clin Gastroenterol Hepatol 2007;5: 111-117.

71. Schroy PC 3rd, Lal S, Glick JT, et al. Patient preferences for colorectal cancer screening: how does stool DNA testing fare? Am J Manag Care 2007;13:393-400.

72. Berger BM, Schroy PC 3rd, Rosenberg JL, et al. Colorectal cancer screening using stool DNA analysis in clinical practice: early clinical experience with respect to patient acceptance and colonoscopic follow-up of abnormal tests. Clin Colorectal Cancer 2006;5:338-343.

73. Zauber AG,Lansdorp-Vogelaar I,Wilschut J, et al. Cost-Effectiveness of DNA Stool Testing to Screen for Colorectal Cancer: Report to AHRQ and CMS from the Cancer Intervention and Surveillance Modeling Network (CISNET) for MISCAN and SimCRC Models. Rockville,MD: Agency for Health Care Quality and Research; 2007:1-84.

74. Osborn NK,Ahlquist DA. Stool screening for colorectal cancer: molecular approaches. Gastroenterology 2005;128:192-206.

75. Woolf SH. A smarter strategy? Reflections on fecal DNA screening for colorectal cancer. N Engl J Med 2004;351:2755-2758.

76. Kutzner N, Hoffmann I, Linke C, et al. Noninvasive detection of colorectal tumours by the combined application of molecular diagnosis and the faecal occult blood test. Cancer Lett 2005; 229:33-41.

77. Levin TR,Farraye FA, Schoen RE,et al. Quality in the technical performance of screening flexible sigmoidoscopy: recommendations of an international multi-society task group. Gut 2005;54: 807-813.

78. Newcomb PA, Norfleet RG, Storer BE, et al. Screening sigmoidoscopy and colorectal cancer mortality. J Natl Cancer Inst 1992; 84:1572-1575.

79. Thiis-Evensen E, Hoff GS, Sauar J, et al. Population-based surveillance by colonoscopy: effect on the incidence of colorectal cancer. Telemark Polyp Study I. Scand J Gastroenterol 1999; 34:414-420.

80. Newcomb PA, Storer BE,Morimoto LM, et al. Long-term efficacy of sigmoidoscopy in the reduction of colorectal cancer incidence. J Natl Cancer Inst 2003;95:622-625.

81. UK Flexible Sigmoidoscopy Screening Trial Investigators. Single flexible sigmoidoscopy screening to prevent colorectal cancer: baseline findings of a UK multicentre randomised trial. Lancet 2002;359:1291-1300.

82. Segnan N, Senore C, Andreoni B, et al. Baseline findings of the Italian multicenter randomized controlled trial of "once-only sigmoidoscopy"-SCORE. J Natl Cancer Inst 2002;94:17631772.

83. Gondal G, Grotmol T, Hofstad B, et al. The Norwegian Colorectal Cancer Prevention (NORCCAP) screening study: baseline findings and implementations for clinical work-up in age groups 50-64 years. Scand J Gastroenterol 2003;38:635-642.

84. Weissfeld JL, Schoen RE, Pinsky PF, et al. Flexible sigmoidoscopy in the PLCO cancer screening trial: results from the baseline screening examination of a randomized trial. J Natl Cancer Inst 2005;97:989-997.

85. Imperiale TF,Wagner DR, Lin CY, et al. Risk of advanced proximal neoplasms in asymptomatic adults according to the distal colorectal findings. N Engl J Med 2000;343:169-174. 
86. Lieberman DA, Weiss DG, Bond JH, et al. Use of colonoscopy to screen asymptomatic adults for colorectal cancer. Veterans Affairs Cooperative Study Group 380. N Engl J Med 2000;343: 162-168.

87. Levin TR,Palitz A,Grossman S, et al. Predicting advanced proximal colonic neoplasia with screening sigmoidoscopy. JAMA 1999;281:1611-1617.

88. Schoenfeld P, Cash B, Flood A, et al. Colonoscopic screening of average-risk women for colorectal neoplasia. N Engl J Med 2005; 352:2061-2068.

89. Regula J, Rupinski M, Kraszewska E, et al. Colonoscopy in colorectal-cancer screening for detection of advanced neoplasia. N Engl J Med 2006;355:1863-1872.

90. Cordice JW Jr, Johnson H Jr. Anatomic distribution of colonic cancers in middle-class black Americans. J Natl Med Assoc 1991;83:730-732.

91. Nelson RL, Dollear T, Freels S,Persky V. The relation of age, race, and gender to the subsite location of colorectal carcinoma. Cancer 1997;80:193-197.

92. Francois F, Park J, Bini EJ. Colon pathology detected after a positive screening flexible sigmoidoscopy: a prospective study in an ethnically diverse cohort. Am J Gastroenterol 2006;101: 823-830.

93. Theuer CP, Taylor TH, Brewster WR, et al. The topography of colorectal cancer varies by race/ethnicity and affects the utility of flexible sigmoidoscopy. Am Surg 2001;67:1157-1161.

94. Atkin W, Rogers $\mathrm{P}$, Cardwell $\mathrm{C}$, et al. Wide variation in adenoma detection rates at screening flexible sigmoidoscopy. Gastroenterology 2004;126:1247-1256.

95. Schoen RE, Pinsky PF,Weissfeld JL, et al. Results of repeat sigmoidoscopy 3 years after a negative examination. JAMA 2003;290:41-48.

96. Doria-Rose VP, Newcomb PA, Levin TR. Incomplete screening flexible sigmoidoscopy associated with female sex, age, and increased risk of colorectal cancer. Gut 2005;54:1273-1278.

97. Schoen RE, Weissfeld JL, Pinsky PF, Riley T. Yield of advanced adenoma and cancer based on polyp size detected at screening flexible sigmoidoscopy. Gastroenterology 2006;131:16831689.

98. Levin TR, Zhao W, Conell C, et al. Complications of colonoscopy in an integrated health care delivery system. Ann Intern Med 2006;145:880-886.

99. Bini EJ, Unger JS,Rieber JM, et al. Prospective, randomized, single-blind comparison of two preparations for screening flexible sigmoidoscopy. Gastrointest Endosc 2000;52:218-222.

100. Zubarik R, Ganguly E, Benway D, et al. Procedure-related abdominal discomfort in patients undergoing colorectal cancer screening: a comparison of colonoscopy and flexible sigmoidoscopy. Am J Gastroenterol 2002;97:3056-3061.

101. Pinsky PF, Schoen RE,Weissfeld JL, et al. Variability in flexible sigmoidoscopy performance among examiners in a screening trial. Clin Gastroenterol Hepatol 2005;3:792-797.

102. Levin TR, Conell C, Shapiro JA, et al. Complications of screening flexible sigmoidoscopy. Gastroenterology 2002;123:17861792.

103. Gross CP,Andersen MS,Krumholz HM,et al. Relation between Medicare screening reimbursement and stage at diagnosis for older patients with colon cancer. JAMA 2006;296:2815-2822.

104. Seeff LC, Richards TB, Shapiro JA, et al. How many endoscopies are performed for colorectal cancer screening? Results from CDC's survey of endoscopic capacity. Gastroenterology 2004; 127:1670-1677.

105. Lewis JD, Asch DA. Barriers to office-based screening sigmoidoscopy: does reimbursement cover costs? Ann Intern Med 1999;130:525-530.
106. Palitz AM, Selby JV, Grossman S, et al. The Colon Cancer Prevention Program (CoCaP): rationale, implementation, and preliminary results. HMO Pract 1997;11:5-12.

107. Rex DK, Imperiale TF, Latinovich DR, Bratcher LL. Impact of bowel preparation on efficiency and cost of colonoscopy. Am J Gastroenterol 2002;97:1696-1700.

108. Takahashi Y,Tanaka H, Kinjo M, Sakumoto K. Sedation-free colonoscopy. Dis Colon Rectum 2005;48:855-859.

109. Muller AD, Sonnenberg A. Prevention of colorectal cancer by flexible endoscopy and polypectomy. A case-control study of 32,702 veterans. Ann Intern Med 1995;123:904-910.

110. Winawer SJ, Zauber AG, Ho MN, et al. Prevention of colorectal cancer by colonoscopic polypectomy. The National Polyp Study Workgroup. N Engl J Med 1993;329:1977-1981.

111. Citarda F, Tomaselli G, Capocaccia R, et al. Efficacy in standard clinical practice of colonoscopic polypectomy in reducing colorectal cancer incidence. Gut 2001;48:812-815.

112. Robertson DJ,Greenberg ER, Beach M, et al. Colorectal cancer in patients under close colonoscopic surveillance. Gastroenterology 2005;129:34-41.

113. Alberts DS,Martinez ME, Roe DJ, et al. Lack of effect of a high-fiber cereal supplement on the recurrence of colorectal adenomas. Phoenix Colon Cancer Prevention Physicians' Network. N Engl J Med 2000;342:1156-1162.

114. Schatzkin A, Lanza E, Corle D, et al. Lack of effect of a low-fat, high-fiber diet on the recurrence of colorectal adenomas. Polyp Prevention Trial Study Group. N Engl J Med 2000;342:1149_ 1155.

115. Leard LE, Savides TJ, Ganiats TG. Patient preferences for colorectal cancer screening. J Fam Pract 1997;45:211-218.

116. Ling BS, Moskowitz MA,Wachs D, et al. Attitudes toward colorectal cancer screening tests. J Gen Intern Med 2001;16:822830.

117. Mysliwiec PA, Brown ML, Klabunde CN, Ransohoff DF. Are physicians doing too much colonoscopy? A national survey of colorectal surveillance after polypectomy. Ann Intern Med 2004; 141:264-271.

118. Pabby A, Schoen RE,Weissfeld JL, et al. Analysis of colorectal cancer occurrence during surveillance colonoscopy in the dietary Polyp Prevention Tr ial. Gastrointest Endosc 2005;61: 385-391.

119. Farrar WD, Sawhney MS, Nelson DB, et al. Colorectal cancers found after a complete colonoscopy. Clin Gastroenterol Hepatol 2006;4:1259-1264.

120. Rex DK, Cutler CS, Lemmel GT, et al. Colonoscopic miss rates of adenomas determined by back-to-back colonoscopies. Gastroenterology 1997;112:24-28.

121. Pickhardt PJ, Nugent PA, Mysliwiec PA, et al. Location of adenomas missed by optical colonoscopy. Ann Intern Med 2004; 141:352-359.

122. Bressler B, Paszat LF, Vinden C, et al. Colonoscopic miss rates for right-sided colon cancer: a population-based analysis. Gastroenterology 2004;127:452-456.

123. Gatto NM, Frucht H, Sundararajan V, et al. Risk of perforation after colonoscopy and sigmoidoscopy: a population-based study. J Natl Cancer Inst 2003;95:230-236.

124. Rex DK, Bond JH,Winawer S, et al. Quality in the technical performance of colonoscopy and the continuous quality improvement process for colonoscopy: recommendations of the US Multi- Society Task Force on Colorectal Cancer. Am J Gastroenterol 2002;97:1296-1308.

125. Faigel DO, Pike IM, Baron TH,et al. Quality indicators for gastrointestinal endoscopic procedures: an introduction. Am J Gastroenterol 2006;101:866-872.

126. Lieberman D, Nadel M, Smith RA, et al. Standardized colonoscopy reporting and data system: report of the Quality Assurance 
Task Group of the National Colorectal Cancer Roundtable. Gastrointest Endosc 2007;65:757-766.

127. Harewood GC, Lieberman DA. Colonoscopy practice patterns since introduction of Medicare coverage for average-r isk screening. Clin Gastroenterol Hepatol 2004;2:72-77.

128. Levin TR. Colonoscopy capacity: Can we build it? Will they come? Gastroenterology 2004;127:1841-1844.

129. Ladabaum U, Song K, Fendrick AM. Colorectal neoplasia screening with virtual colonoscopy: when, at what cost, and with what national impact? Clin Gastroenterol Hepatol 2004;2:554563.

130. Vijan S, Inadomi J, Hayward RA, et al. Projections of demand and capacity for colonoscopy related to increasing rates of colorectal cancer screening in the United States. Aliment Pharmacol Ther 2004;20:507-515.

131. Boolchand V, Olds G, Singh J, et al. Colorectal screening after polypectomy: a national survey study of primary care physicians. Ann Intern Med 2006;145:654-659.

132. Smith RA, Cokkinides V, Eyre HJ. American Cancer Society guidelines for the early detection of cancer, 2003. CA Cancer J Clin 2003;53:27-43.

133. Glick SN, Ralls PW,Balfe DM, et al. Screening for colorectal cancer. American College of Radiology. ACR Appropriateness Criteria. Radiology 2000;215(suppl):231-237.

134. Colorectal Cancer Screening Tests: Conditions for and Limitations on Coverage, 62 Federal Register 410.37 (1997).

135. Glick S. Double-contrast barium enema for colorectal cancer screening: a review of the issues and a comparison with other screening alternatives. AJR Am J Roentgenol 2000;174:15291537.

136. de Zwart IM, Griffioen G, Shaw MP, et al. Barium enema and endoscopy for the detection of colorectal neoplasia: sensitivity, specificity, complications and its determinants. Clin Radiol 2001;56:401-409.

137. Kelvin FM, Gardiner R, Vas W, Stevenson GW. Colorectal carcinoma missed on double contrast barium enema study: a problem in perception. AJR Am J Roentgenol 1981;137:307-313.

138. Thorpe CD, Grayson DJ Jr,Wingfield PB. Detection of carcinoma of the colon and rectum by air contrast enema. Surg Gynecol Obstet 1981;152:307-309.

139. Fork FT, Lindström C, Ekelund G. Double contrast examination in carcinoma of the colon and rectum. A prospective clinical series. Acta Radiol Diagn (Stockh) 1983;24:177-188.

140. Johnson CD, Carlson HC, Taylor WF, Weiland LP. Barium enemas of carcinoma of the colon: sensitivity of double- and singlecontrast studies. AJR Am J Roentgenol 1983;140:1143-1149.

141. Reiertsen O, Bakka A,Tronnes S, Gauperaa T. Routine double contrast barium enema and fiberoptic colonoscopy in the diagnosis of colorectal carcinoma. Acta Chir Scand 1988;154:5355.

142. Thomas RD, Fairhurst JJ, Frost RA.Wessex regional radiology audit: barium enema in colorectal carcinoma. Clin Radiol 1995; 50:647-650.

143. Rex DK, Rahmani EY, Haseman JH, et al. Relative sensitivity of colonoscopy and barium enema for detection of colorectal cancer in clinical practice. Gastroenterology 1997;112:17-23.

144. Strøm E, Larsen JL. Colon cancer at barium enema examination and colonoscopy: a study from the county of Hordaland, Norway. Radiology 1999;211:211-214.

145. Gillespie JS,Kelly BE. Double contrast barium enema and colorectal carcinoma: sensitivity and potential role in screening. Ulster Med J 2001;70:15-18.

146. McDonald $S$, Lyall $P$, Israel $L$, et al. Why barium enemas fail to identify colorectal cancers. ANZ J Surg 2001;71:631-633.

147. Connolly DJ,Traill ZC, Reid HS, et al. The double contrast barium enema: a retrospective single centre audit of the detection of colorectal carcinomas. Clin Radiol 2002;57:29-32.
148. Leslie A, Virjee JP. Detection of colorectal carcinoma on double contrast barium enema when double reporting is routinely performed: an audit of current practice. Clin Radiol 2002;57:184187.

149. Tan KY, Seow-Choen F, Ng C, et al. Which colorectal cancers are missed by double contrast barium enema? Tech Coloproctol 2004;8:169-172.

150. Tawn DJ, Squire CJ,Mohammed MA,Adam EJ. National audit of the sensitivity of double-contrast barium enema for colorectal carcinoma, using control charts: For the Royal College of Radiologists Clinical Radiology Audit Sub-Committee. Clin Radiol 2005;60:558-564.

151. Williams CB, Macrae FA, Bartram Cl. A prospective study of diagnostic methods in adenoma follow-up. Endoscopy 1982; $14: 74-78$

152. Winawer SJ, Stewart ET, Zauber AG, et al. A comparison of colonoscopy and double-contrast barium enema for surveillance after polypectomy. National Polyp Study Work Group. N Engl J Med 2000;342:1766-1772.

153. Zauber AG,Winawer S, Stewart ET. Author reply. N Engl J Med 2000;343:1729-1730.

154. Blakeborough A, Sheridan MB, Chapman AH. Complications of barium enema examinations: a survey of UK Consultant Radiologists 1992 to 1994. Clin Radiol 1997;52:142-148.

155. American College of Radiology. Appropriateness Criteria for the Barium Enema. Reston, VA: American College of Radiology; 2004.

156. El-Serag HB, Petersen L, Hampel H, et al. The use of screening colonoscopy for patients cared for by the Department of Veterans Affairs. Arch Intern Med 2006;166:2202-2208.

157. Ferrucci JT. Double-contrast barium enema: use in practice and implications for CT colonography. AJR Am J Roentgenol 2006; 187:170-173.

158. Robertson RH, Burkhardt JH, Powell MP, et al. Trends in colon cancer screening procedures in the US Medicare and Tricare populations: 1999-2001. Prev Med 2006;42:460-462.

159. Zalis ME, Perumpillichira J, Del Frate C, Hahn PF. CT colonography: digital subtraction bowel cleansing with mucosal reconstruction initial observations. Radiology 2003;226:911-917.

160. Iannaccone R, Laghi A, Catalano $C$, et al. Computed tomographic colonography without cathartic preparation for the detection of colorectal polyps. Gastroenterology 2004;127: 1300-1311.

161. Lefere P,Gryspeerdt S,Marrannes J, et al. CT colonography after fecal tagging with a reduced cathartic cleansing and a reduced volume of barium. AJR Am J Roentgenol 2005;184:18361842.

162. Hara AK, Johnson CD, Reed JE, et al. Detection of colorectal polyps with CT colography: initial assessment of sensitivity and specificity. Radiology 1997;205:59-65.

163. Fenlon HM, Nunes DP, Schroy PC 3rd, et al. A comparison of virtual and conventional colonoscopy for the detection of colorectal polyps. N Engl J Med 1999;341:1496-1503.

164. Yee J,Akerkar GA,Hung RK,et al. Colorectal neoplasia: performance characteristics of CT colonography for detection in 300 patients. Radiology 2001;219:685-692.

165. Cotton PB, Durkalski VL, Pineau BC, et al. Computed tomographic colonography (virtual colonoscopy): a multicenter comparison with standard colonoscopy for detection of colorectal neoplasia. JAMA 2004;291:1713-1719.

166. Rockey DC,Paulson E, Niedzwiecki D, et al. Analysis of air contrast barium enema, computed tomographic colonography, and colonoscopy: prospective comparison. Lancet 2005;365: 305-311.

167. Pickhardt PJ, Choi JR, Hwang I, et al. Computed tomographic virtual colonoscopy to screen for colorectal neoplasia in asymptomatic adults. N Engl J Med 2003;349:2191-2200. 
168. Halligan S,Altman DG,Taylor SA, et al. CT colonography in the detection of colorectal polyps and cancer: systematic review, meta-analysis, and proposed minimum data set for study level reporting. Radiology 2005;237:893-904.

169. Mulhall BP,Veerappan GR, Jackson JL. Metaanalysis: computed tomographic colonography. Ann Intern Med 2005;142: 635-650.

170. Cash B, Kim C, Cullen P, et al. Accuracy of computed tomographic colonography for colorectal cancer screening in asymptomatic individuals [abstract]. Gastroenterology 2006;130: A46. Abstract 278 .

171. Graser A, Kolligs F, Kramer H, et al. Results from the "Munich Colorectal Cancer Prevention Tr ial": comparison of low-dose 64-MDCT colonography and video colonoscopy in a screening population [abstract]. Presented at: European Society of Gastrointestinal and Abdominal Radiology/Society of Gastrointestinal Radiologists; June 19-23, 2006; Crete, Greece. European Radiology Supplements 2006;26(suppl):C19-C27.

172. Kim DH, Pickhardt PJ, Taylor AJ, et al. CT colonography versus colonoscopy for the detection of advanced neoplasia. N Engl J Med 2007;357:1403-1412.

173. Knechtges PM, McFarland BG, Keysor KJ, et al. National and local trends in CT colonography reimbursement: past, present, and future. J Am Coll Radiol 2007;4:776-799.

174. Pickhardt PJ, Taylor AJ, Kim DH, et al. Screening for colorectal neoplasia with CT colonography: initial experience from the 1st year of coverage by third-party payers. Radiology 2006;241: 417-425.

175. Fidler JL, Johnson CD,MacCarty RL, et al. Detection of flat lesions in the colon with CT colonography. Abdom Imaging 2002;27:292-300.

176. Pickhardt PJ, Nugent PA, Choi JR, Schindler WR. Flat colorectal lesions in asymptomatic adults: implications for screening with CT virtual colonoscopy. AJR Am J Roentgenol 2004;183: 13431347.

177. Bond JH. Doubling time of flat and polypoid colorectal neoplasms: defining the adenomacarcinoma sequence. Am J Gastroenterol 2000; 95:1621-1623.

178. Zauber AG, O'Brien MJ,Winawer SJ. On finding flat adenomas: is the search worth the gain? Gastroenterology 2002;122:839840.

179. Park SH, Lee SS, Choi EK, et al. Flat colorectal neoplasms: definition, importance, and visualization on CT colonography. AJR Am J Roentgenol 2007;188:953-959.

180. Gupta S, Durkalski V, Cotton P,Rockey DC. Variation of agreement in polyp size measurement between computed tomographic colonography and pathology assessment: clinical implications. Clin Gastroenterol Hepatol 2008;6:220-227.

181. Pickhardt PJ, Lee AD, McFarland EG,Taylor AJ. Linear polyp measurement at CT colonography: in vitro and in vivo comparison of two-dimensional and three-dimensional displays. Radiology 2005;236:872-878.

182. Park SH, Choi EK, Lee SS, et al. Polyp measurement reliability, accuracy, and discrepancy: optical colonoscopy versus CT colonography with pig colonic specimens. Radiology 2007;244: 157-164.

183. Young BM, Fletcher JG, Paulsen SR, et al. Polyp measurement with CT colonography: multiple- reader, multiple-workstation comparison. AJR Am J Roentgenol 2007;188:122-129.

184. Amis ES Jr, Butler PF, Applegate KE, et al. American College of Radiology white paper on radiation dose in medicine. J Am Coll Radiol 2007;4:272-284.

185. Brenner DJ, Hall EJ. Computed tomography — an increasing source of radiation exposure. N Engl J Med 2007;357:22772284.

186. Ron E. lonizing radiation and cancer risk: evidence from epidemiology. Radiat Res 1998;150:S30-S41.
187. Health Physics Society. Radiation Risk in Perspective. Position Statement of the Health Physics Society. McLean, VA: Health Physics Society; 2004. Available at: www.hps.org/documents/ risk_ps010-1.pdf. Accessed January 30, 2008.

188. Brenner DJ, Georgsson MA. Mass screening with CT colonography: should the radiation exposure be of concern? Gastroenterology 2005;129:328-337.

189. Macari M, Bini EJ, Xue X, et al. Colorectal neoplasms: prospective comparison of thin-section low-dose multi-detector row CT colonography and conventional colonoscopy for detection. Radiology 2002;224:383-392.

190. American College of Radiology. ACR Practice Guideline for the Performance of Computed Tomography (CT) Colonography in Adults. Reston,VA: American College of Radiology; 2006.

191. Pickhardt PJ. Incidence of colonic perforation at CT colonography: review of existing data and implications for screening of asymptomatic adults. Radiology 2006;239:313-316.

192. Burling D, Halligan S, Slater A, et al. Potentially serious adverse events at CT colonography in symptomatic patients: national survey of the United Kingdom. Radiology 2006;239:464-471.

193. Sosna J, Blachar A, Amitai M, et al. Colonic perforation at CT colonography: assessment of risk in a multicenter large cohor $t$ Radiology 2006;239:457-463.

194. Hara AK, Johnson CD, MacCarty RL, Welch TJ. Incidental extracolonic findings at CT colonography. Radiology 2000;215:353357.

195. Gluecker TM,Johnson CD,Wilson LA, et al. Extracolonic findings at CT colonography: evaluation of prevalence and cost in a screening population. Gastroenterology 2003;124:911-916.

196. Yee J,Kumar NN, Godara S, et al. Extracolonic abnormalities discovered incidentally at CT colonography in a male population. Radiology 2005;236:519-526.

197. Pickhardt PJ,Taylor AJ. Extracolonic findings identified in asymptomatic adults at screening CT colonog raphy. AJR Am J Roentgenol 2006;186:718-728.

198. Lieberman D. A call to action-measuring the quality of colonoscopy. N Engl J Med 2006;355:2588-2589.

199. Zalis ME, Barish MA, Choi JR, et al. CT colonography reporting and data system: a consensus proposal. Radiology 2005;236: 3-9.

200. Kim DH, Pickhardt PJ, Hoff G, Kay CL. Computed tomographic colonography for colorectal screening. Endoscopy 2007;39: 545-549.

201. Kim DH, Pickhardt PJ, Taylor AJ. Characteristics of advanced adenomas detected at CT colonographic screening: implications for appropriate polyp size thresholds for polypectomy versus surveillance. AJR Am J Roentgenol 2007;188:940-944.

202. Moravec M, Lieberman D, Holub J, et al. Rate of advanced pathologic features in $6-9 \mathrm{~mm}$ polyps in patients referred for colonoscopy screening. Gastrointest Endosc 2007;65:822.

203. Rex DK, Lieberman D. ACG colorectal cancer prevention action plan: update on CT-colonography. Am J Gastroenterol 2006; 101:1410-1413.

204. Rockey DC, Barish M, Brill JV, et al. Standards for gastroenterologists for performing and interpreting diagnostic computed tomographic colonography. Gastroenterology 2007;133:10051024.

205. Pignone M, Saha S, Hoerger T, Mandelblatt J. Cost-effectiveness analyses of colorectal cancer screening: a systematic review for the US Preventive Services Task Force. Ann Intern Med 2002;137:96-104.

206. Song K, Fendrick AM, Ladabaum U. Fecal DNA testing compared with conventional colorectal cancer screening methods: a decision analysis. Gastroenterology 2004;126:1270-1279.

207. Wu GH,Wang YM, Yen AM, et al. Costeffectiveness analysis of colorectal cancer screening with stool DNA testing in intermediate-incidence countries. BMC Cancer 2006;6:136. 
208. Pickhardt PJ, Hassan C, Laghi A, et al. Costeffectiveness of colorectal cancer screening with computed tomography colonography: the impact of not reporting diminutive lesions. Cancer 2007;109:2213-2221.

209. Agrawal S, Bhupinderjit A, Bhutani MS, et al. Colorectal cancer in African Americans. Am J Gastroenterol 2005;100:515-523.

210. American College of Obstetricians and Gynecologists. ACOG Committee Opinion No. 384 November 2007: colonoscopy and colorectal cancer screening and prevention. Obstet Gynecol 2007;110:1199-1202.

ACS CRC Advisory Group Members: Bernard Levin, MD (Chair); Professor Emeritus, The University of Texas MD Anderson Cancer Center, Houston, TX; Tim Byers, MD, MPH (Vice Chair); Professor, Preventive Medicine and Biometrics, University of Colorado Health Sciences Center, Denver, CO; Briggs W. Andrews, Esq; Senior Vice President; and General Counsel of Carilion Health System, Roanoke, VA; Elvan Daniels, MD; Associate Director for CommunityOriented Primary Care, Morehouse School of Medicine, Atlanta, GA; Lovell Jones, PhD; Professor of Gynecologic Oncology; and Director, Center of Excellence for Research on Minority Health, The University of Texas MD Anderson Cancer Center, Houston, TX; Gordon Klatt, MD; Medical Director, Cancer Programs, Mt. Rainier Surgical Association, Tacoma, WA; Theodore R. Levin, MD; Staff Physician, Gastroenterology Department, Kaiser Permanente Walnut Creek Medical Center, Walnut Creek, CA; Pamela McAllister, PhD; Founding Member and Research Advocate, Colorectal Cancer Coalition, Madison, WI; Beth McFarland, MD; Adjunct Professor, Mallinckrodt Institute of Radiology, St Luke's Hospital, Diagnostic Imaging Associates, Chesterfield, MO; Sigurd Normann, MD, PhD; Professor, Department of Pathology, Immunology and Laboratory Medicine, University of Florida, Gainesville, FL; Miquel Rodriguez-Bigas, MD; Professor of Surgery, Department of Surgical Oncology, The University of Texas MD Anderson Cancer Center, Houston, TX; Alan Thorson, MD; Associate Professor of Surgery; and Program Director, Section of Colon and Rectal Surgery, Creighton University School of Medicine; and Clinical Associate Professor of Surgery, University of Nebraska College of Medicine, Omaha, NE; Richard Wender, MD; Chair; and Alumni Professor, Department of Family and Community Medicine, Thomas Jefferson University, Philadelphia, PA.

ACS Staff and Consultants: Durado Brooks, MD, MPH; Director, Prostate and CRC, Cancer Control Science Department, American Cancer Society, Atlanta, GA; Robert A. Smith, PhD; Director, Cancer Screening, Cancer Control Science Department, American Cancer Society, Atlanta, GA; Kimberly S. Andrews; Research Associate, Cancer Control Science Department, American Cancer Society, Atlanta, GA; Chiranjeev Dash, MBBS, MPH; Doctoral Candidate, Department of Epidemiology, Emory University, Rollins School of Public Health, Atlanta, GA.

US Multi-Society Task Force Members: David A. Lieberman, MD; Chief, Division of Gastroenterology, Oregon Health and Science
University, Portland Veterans Medical Center, Portland, OR; Francis M. Giardiello, MD; John G. Rangos Sr Professor of Medicine, Johns Hopkins University School of Medicine, Baltimore, MD; Theodore R. Levin, MD; Staff Physician, Gastroenterology Department, Kaiser Permanente Walnut Creek Medical Center, Walnut Creek, CA; Douglas K. Rex, MD; Professor of Medicine, Indiana University, Indianapolis, IN; Clyde Watkins, Jr, MD; Physician, Capstone Medical Group PC, Lithonia, GA; Sidney J. Winawer, MD; Attending Physician, Memorial Sloan-Kettering Cancer Center, New York, NY.

American College of Radiology Colon Cancer Committee Members: Beth McFarland, MD; Adjunct Professor, Mallinckrodt Institute of Radiology, St Luke's Hospital, Diagnostic Imaging Associates, Chesterfield, MO; Seth Glick, MD; Clinical Professor of Radiology, University of Pennsylvania Health System, Philadelphia, PA; Perry Pickhardt, MD; Associate Professor, Radiology Department, University of Wisconsin Hospital and Clinics, Madison, WI.

This article is being published jointly in 2008 in CA: A Cancer Journal for Clinicians (online: March 5, 2008; print: May/June 2008), Gastroenterology (online: March 31, 2008; print: May, 2008), and Radiology (June, 2008) by the American Cancer Society, the American Gastroenterological Association (AGA) Institute, and the Radiological Society of North America.

Authors J. Bond, D. Johnson and C.D. Johnson were not included as authors in the $C A$ online version of this paper published on March 5 The authors were subsequently added and will appear in the May/June 2008 printed version of $C A$ along with an erratum. Also, The American Gasteroenterological Association (AGA) Institute was misidentified as the American Gasteroenterology Association in the CA online version of this paper. This will also be corrected in a CA erratum.

Workgroup members were asked to disclose relationships, including potential financial conflicts of interest. The following was disclosed: D. Lieberman served on the scientific advisory board for Exact Sciences, ending September 30, 2007. B. McFarland receives honoraria for serving on the medical advisory boards for Vital Images and Medicsight. P. Pickhardt serves as a paid consultant to Covidien, Viatronix, Fleet, Medicsight, and Philips. D. Rex receives an honorarium for serving as a speaker and research support for serving as an investigator for Olympus; serves on the scientific advisory board and receives research support for serving as an investigator for Given Imaging; and serves on the scientific advisory boards for Avantis, NeoGuide, G.I. View, and American BioOptics. M. Rodriguez-Bigas receives an honorarium for serving on the speaker's bureau for Genzyme. R. Wender serves on the scientific advisory boards for Epigenomics, GeneNews, and G.I. View, but receives no personal income for doing so.

We wish to acknowledge the role of the advisory committees, external experts, and helpful comments and recommendations from reviewers and organizational representatives who reviewed various drafts of this document. 